\title{
Periodificación en Arqueología peruana: genealogía y aporía
}

Périodisation en Archéologie péruvienne : généalogie et aporie

Periodization in Peruvian archaeology: genealogy and apory

\section{Gabriel Ramón Joffré}

\section{OpenEdition}

Journals

Edición electrónica

URL: https://journals.openedition.org/bifea/5567

DOI: $10.4000 /$ bifea. 5567

ISSN: 2076-5827

Editor

Institut Français d'Études Andines

Edición impresa

Fecha de publicación: 1 mayo 2005

Paginación: 5-33

ISSN: 0303-7495

Referencia electrónica

Gabriel Ramón Joffré, «Periodificación en Arqueología peruana: genealogía y aporía», Bulletin de I'Institut français d'études andines [En línea], 34 (1) | 2005, Publicado el 08 abril 2005, consultado el 31 enero 2022. URL: http://journals.openedition.org/bifea/5567 ; DOI: https://doi.org/10.4000/bifea.5567

\section{(@) $\Theta \Theta \Theta$}

Les contenus du Bulletin de l'Institut français d'études andines sont mis à disposition selon les termes de la licence Creative Commons Attribution - Pas d'Utilisation Commerciale - Pas de Modification 4.0 International. 


\title{
Periodificación en arqueología peruana: genealogía y aporía
}

\author{
Gabriel Ramón Joffré*
}

\begin{abstract}
Resumen
La periodificación es un estratégico punto de intersección entre la propuesta teórica y la investigación empírica. Su historia resume bien los debates por los que ha atravesado la arqueología peruana. La variedad de periodificaciones postuladas y/o practicadas en el área central andina, las convierte en un privilegiado campo de estudio. Asumida la necesaria reciprocidad entre el avance de toda disciplina y el conocimiento de su historia, se plantea este recorrido por los principales sistemas de periodificación, los enfrentamientos entre tendencias y el panorama actual. No se trata de un enfoque teórico, antes bien historiográfico de un aspecto específico de la arqueología peruana. El objetivo es hacer una genealogía crítica y funcional, es decir presentar la génesis de los esquemas conceptuales actualmente utilizados, sus conexiones y límites.
\end{abstract}

Palabras claves - Historia de la arqueología peruana, historiografía arqueológica, periodificación, sistemas de clasificación, Perú

\section{Périodisation en archéologie péruvienne : généalogie et aporie}

\section{Résumé}

La périodisation est un point stratégique d'intersection entre la théorie et la recherche empirique. Son histoire au Pérou résume bien les débats expérimentés par l'archéologie péruvienne. La variété des périodisations postulées et pratiquées dans les Andes l'a transformée en un champ d'étude privilégié. Une fois assumée la réciprocit nécessaire entre le développement d'une discipline et la connaissance de son histoire, l'auteur se livre à cette enquête sur les principaux systèmes de periodisation, les 
affrontements entre les tendances et le panorama actuel. Ce n'est pas un travail théorique, mais plutôt historiographique sur un aspect spécifique de l'archeologie péruvienne. L'objectif est de faire une généalogie critique et fonctionnelle, c'est-à-dire présenter la genèse des schémas conceptuels utilisés aujourd'hui, leurs liens et leurs limites.

Mots clés - Histoire de l'archéologie péruvienne, historiographie archéologique, périodisation, systèmes de classification, Pérou

\title{
Periodization in Peruvian archaeology: genealogy and apory
}

\begin{abstract}
Periodization is a strategic point of intersection between theory and empirical research. Its history reflects the debates which have taken place in Peruvian archaeology. The variety of periodizations postulated and/or practiced in the central Andean area, make it a privileged field of study. Assuming the necessary reciprocal relationship between the advance of every discipline and the knowledge of its history, this survey reviews the main periodization systems, the confrontations between differing tendencies, and the current panorama. This is historiograhic rather than a theoretical work about one specific aspect of Peruvian archaeology. The objective is to construct a critical and functional genealogy; that is, to present the genesis of the conceptual schemes used now, as well as their connections and limits.
\end{abstract}

Key words - History of Peruvian Archaeology, archaeological historiography, periodization, classification systems, Peru

What's in a name? That which we call a rose By any other word would smell as sweet.

William Shakespeare [1597] Romeo y Julieta, acto 2, escena 1

\begin{abstract}
Vale recordar, que los cambios interpretativos en la arqueología peruana (y probablemente en cualquier arqueología) resultan menos de la necesidad de explicar o clasificar nuevos datos, que del estímulo de ideas con antecedentes en la tradición cultural del propio arqueólogo, no derivadas de los especímenes.
\end{abstract}

John Rowe 1951: 356

En una entrevista concedida en 1997, un arqueólogo peruano relató una curiosa anécdota: tras sucesivas reediciones, los editores estadounidenses de su manual sobre arqueología andina le solicitaron (en 1992) que lo revisara. El autor pidió que dejaran de publicarlo. Esta renuncia pasaría desapercibida si no se tratara de un clásico local: De los pueblos, de las culturas y las artes 
del Antiguo Perú de Luis Lumbreras1. Esta síntesis fue un hito en la arqueología nacional y su impronta ha resultado decisiva en esta disciplina. Su eficacia estaba íntimamente vinculada a la propuesta de periodificación ensayada en trabajos anteriores (Lumbreras, 1969a) y consagrada en aquella publicación (Lumbreras, 1969b). Luego de tres décadas, e incluso después de la renuncia del propio autor, resulta significativo que el esquema planteado en este libro perdure prácticamente incólume como referencia para muchos especialistas — mayormente locales - dedicados a la historia de los Andes centrales prehispánicos. De los pueblos.... resultó de la estudiada organización de un gran corpus informativo en un esquema evolutivo, sintetizado en su multicitado cuadro cronológico. Sin obviar méritos intrínsecos, entre los diversos motivos para explicar la permanencia de esta propuesta, no puede descartarse la posterior desatención a este tópico. Complementariamente: es preciso interrogarse por el papel de la periodificación para la arqueología peruana actual, no como ornamento, antes bien como trama del razonamiento arqueológico.

Por tradición - y presupuesto- las investigaciones en el área andina se han centrado en determinados sitios o valles. De modo que la abundante información monográfica contrasta con la escasez de trabajos de síntesis (Bonavia, 1991: 6). Y cuando ocasionalmente aparecen, es obvio que pese a la abundante información ofrecida, suelen flaquear en su mecánica interna, es decir, en la nomenclatura y la periodificación. Esto opaca la relación entre corpus e hipótesis. Sin embargo, la importancia de la periodificación no se restringe a las obras generales, siendo relevante desde el grado cero de la investigación arqueológica. Para organizar la información obtenida por los más diversos medios (excavación, prospección, estudio de colecciones, etc.) los arqueólogos utilizan — tácita y/o explícitamentecategorías alusivas al tiempo y al espacio, que son las coordenadas de la periodificación (y de la arqueología). Se trata de un paso previo -imprescindible - a la síntesis, y de la columna vertebral de la disciplina, que permite clasificar significativamente las «culturas», explicar los «procesos» e identificar los «sistemas». Conviene entonces aludir a los motivos de la escasa atención al tema.

Al pasar de la época de las grandes síntesis (típicas de la denominada corriente históricocultural) a la de los problemas específicos (que caracteriza el enjambre de tendencias posteriores), se soslayó la periodificación, ya que había llegado el momento de analizar casos puntuales, de limitarse a las explicaciones sincrónicas2. Por lo menos en nuestro medio, la actitud asumida en este trance acarreó una falacia (que la atención a problemas determinados permite obviar su división temporal específica y comparada) y tuvo algunas consecuencias:

a. la permanencia (directa o indirecta) de las categorías planteadas en la primera época;

b. la falta de discusión respecto a los criterios de organización informativa al interior de cada sección específica (léase «cultura»)

c. la proliferación de híbridos que tratan de acoplar nueva información en categorías teórica (y prácticamente) enrarecidas 3.

1 La entrevista fue concedida a Manuel Cisneros y titulada «Tenemos que vivir, cambiar y avanzar» (El Comercio. Suplemento Dominical. 12.1.1997). El libro fue publicado en castellano en 1969 y traducido al inglés en 1974, por Betty Meggers. En su reseña Browman (1976) lista las modificaciones introducidas en la traducción. Ver también Rouse (1975).

2 Una descripción sintética de este cambio en Renfrew \& Bahn, 1993: 34-7.

3 Complementariamente, podría mencionarse algunas consecuencias concretas, como — por ejemplo- que se haya vuelto lugar común acoplar en una misma secuencia criterios tan distintos como «Horizonte Temprano» y «Formativo Superior»; considerar equivalentes el «Intermedio Temprano» y el estadio de los «Desarrollos Regionales»; o aludir al «Periodo Formativo». 
Parte del indicado conflicto reside en la ausencia de perspectiva histórica elemental. Para plantear la discusión sobre esta herramienta conceptual en la arqueología peruana y ajustar algunos cabos, se ensayará su genealogía razonada. Pese a lo mucho que puede haberse modificado esta disciplina en las últimas décadas, la inclusión de «cuadros» o esquemas, es una constante. El espacio andino ha sido objeto de recurrentes periodificaciones, lo que permite trazar una historia particularmente densa de este tópico ${ }^{4}$. Dada su continuidad, la comparación de estos esquemas es útil para conocer ¿cómo?, ¿̇en qué?, e incluso ¿por qué? han variado las interpretaciones acerca del pasado andino ${ }^{5}$.

A grandes rasgos, podría decirse que en nuestro medio han primado dos formas de periodificar o clasificar temporalmente el material arqueológico: la evolutiva y la cronológica. Quienes optaron por la primera, han preferido los estadios para organizar sus investigaciones, ordenando sus categorías en base a criterios económicos o políticos. En el segundo caso, se considera al periodo como elemento organizativo clave, no otorgándole más valor que el estrictamente cronológico. No se trata de propuestas excluyentes, pero es preciso distinguirlas 6 . La falta de atención sobre este tema es causa y efecto de graves incongruencias, manifiestas en las investigaciones, en las publicaciones y especialmente en los guiones de los museos. Las recurrentes críticas a las incoherencias en la nomenclatura y la periodificación (Kroeber, 1942; Schaedel en Varios, 1959; Lumbreras, 1981: 22, inter alia) no han implicado — ni implican- desconocer su valor como instrumento metodológico.

\section{ARQUEÓLOGOS EN BUSCA DE HORIZONTES 7}

Luego de una primera etapa principalmente dedicada a organizar las colecciones americanas de algunos museos de su tierra natal, y escribir un par de libros sobre el tema, Max Uhle

4 Listas comentadas de cuadros en: Valcárcel (1967: 56-57, 223-251), Ravines (1970: 13-24), Willey (1971) y Silva (2000). Por diversos motivos, pero especialmente desde que fue declarada algo así como «área núclear» del subcontinente, la zona andina ha recibido una atención deferente, manifiesta en una abundante bibliografía arqueológica. Para contrastar con las supuestas «áreas periféricas» sudamericanas, véase el manual de Prous (1992) para Brasil, y el de Ottonello \& Lorandi (1987) para Argentina.

5 La historia de la arqueología peruana ha sido tratada desde las más diversas perspectivas. Aquí solo se abordará un rasgo particular. Un marco general inicial, antiguo pero perceptivo en Porras (1963: 72-103). Pese a sus obvias divergencias —o gracias a ellas — han resultado especialmente útiles los planteamientos de Fung (1965), Patterson (1989) y Makowski (1995): tres nacionalidades, décadas y propuestas distintas. El primero es valioso por las explicaciones prácticas de los métodos usados por los arqueólogos peruanistas, el segundo brinda un contexto social general y el tercero una panorámica sistematización de autores/escuelas. Otros recuentos historiográficos en: Burger (1989a), Lumbreras (1969b: 20-27; 1990), Matos (1990), Schaedel \& Shimada (1982). Un informativo mea culpa en Isbell (1995).

6 Cardoso (1982: 206-208) ubica dos posiciones básicas: los realistas y los convencionalistas. Los primeros sostienen que la periodificación proviene de la naturaleza del objeto investigado. De modo que si son adecuadamente establecidos, los periodos constituyen un reflejo de la realidad histórica. Los otros creen que cualquier periodificación es arbitraria, justificable solo por razones prácticas o didácticas. Sobre el papel crucial de la periodificación (y su coherencia interna) en la historia, ver Panofsky (1991 [1951]: 1-2). Una discusión sobre los límites de la periodificación, que además incide en la arqueología americana (y peruana) en Kubler (1985 [1970]) y Stone-Miller (1993), aunque (en este último caso) los cuadros discutidos no sean los más significativos. Nachtingal (1969) aborda el tema para el Perú, pero desordenadamente.

7 La distinción de los restos materiales incas/preincas, se remonta -al menos- a fines del siglo dieciocho. Sin embargo, no es posible abordar aquí esta protohistoria de la arqueología peruana, que incluiría a los viajeros-excavadores (v.g. Squier) y a los primeros sistematizadores de la historia prehispánica (v.g. Lorente). Esta sección se limita a las cuatro décadas iniciales del siglo veinte. 
(1856-1944) viajó a los Andes8. Entre los múltiples aportes de este sinólogo alemán, valga citar dos. Primero, la excavación sistemática en Pachacamac (1896-1897) que le permitió reconocer la superposición de tumbas, que sirvió de base para la primera secuencia cronológica estratigráficamente sustentada. Uhle corroboró su experiencia museográfica previa, distinguiendo entre el material Tiahuanaco e Inca, y ubicando entre ellos los estilos epigonales. En segundo lugar, al observar la relativa ubicuidad sincrónica de determinados estilos, acuñó el concepto de «horizontes cronológicos». Estos le sirvieron para organizar el material hallado durante sus excavaciones por el territorio andino (Uhle, 1902)9. Entre 1899 y 1900, con el apoyo de la Universidad de California, trabajó en los valles de Ica y Nazca al sur y de Moche en el norte. Así ratificó su propuesta y ubicó los estilos Proto Chimú y Proto Nazca antes de Tiahuanaco. Finalmente identificó poblaciones de «pescadores incultos» en distintas zonas de la costa, caracterizadas por la presencia de conchales. Todo esto permitió a Uhle (1970 [1910]) contar con sustento para su primera periodificación:

- Imperio Incaico

- Estilos Epigonales de Tiahuanaco

- Cultura Tiahuanaco

- Culturas Protoides (Proto Chimú, Proto Nazca)

- Pescadores primitivos del litoral

Entre los diversos debates académicos de Uhle, el menos tratado ha sido el que sostuvo con Philip A. Means, autor de varios libros de síntesis sobre el Perú10. Como respuesta a un ácido artículo — donde este historiador norteamericano crtiticaba su cuadro cronológicoUhle decidió presentarlo y sustentarlo en detalle. En este documento no solo amplía la información sobre la costa central sino del área andina en general, en la que es posible distinguir la recurrencia de ciertas manifestaciones culturales (ver cuadro cronológico en Uhle, 1920: 458)11.

Dedicado a la arqueología, pero principalmente en paises vecinos (Chile, Ecuador), Uhle continuará defendiendo su esquema cronológico general, sin alterar sus rasgos esenciales (cf. 1955 [1939]). Complementariamente, la labor de organizar y estudiar las colecciones recolectadas durante sus excavaciones quedará en manos de Alfred L. Kroeber (1876-1960). Este antropólogo norteamericano y sus colaboradores (Anna Gayton, Lila O’Neale, William Strong) asumirán la publicación sistemática del material de Uhle, complementándola con

8 La novedad de la obra de Uhle resalta en comparación con sus precedentes continentales. Ver las observaciones de Rowe (1998). Un recuento de las discusiones que conforman el antecedente inmediato de la arqueología en el Perú, en el estudio de Riviale (2000) sobre los viajeros franceses. Lamentablemente el autor no plantea preguntas específicas respecto a la investigación arqueológica. Algunas observaciones en este sentido, en Ramón (2000).

9 La biografía modelo de Uhle en Rowe (1954). Sobre lo indicado ver también Fung (1965: 90-92), y especialmente Rowe (1998: 17).

10 Un presentación de la polémica en Rowe (1960c). Simultáneamente a Uhle, algunos historiadores plantearon sus propias periodificaciones, como Clements Markham en 1910, Carlos Wiesse en 1913 y Philip Means en 1917. Ver los cuadros en Ravines (1970: 13). Si bien el primero resulta un esfuerzo «pre-arqueológico» pionero, los dos últimos se vinculan íntimamente al trabajo del arqueólogo alemán. Según Uhle (1920: 448), él entregó su cuadro de periodificación a Wiesse para sus clases universitarias, y Means lo usó tergiversadamente.

11 Ya que de alguna manera este artículo es también la comparación entre cuadros cronológicos arqueológicos y sus contextos, he especificado la ubicación exacta de los mismos para auxiliar al lector interesado. Remito a las fuentes originales, ya que no son de dificil acceso, y su adecuada reproducción habría incrementado excesivamente la extensión de este texto. Finalmente no creo necesario presentar un esquema que resuma o compare gráficamente los cuadros discutidos, ya que -como precisamente trato de demostrar aquí- en muchos casos son gráficos cualitativamente distintos. 
expediciones al Perú. Uhle había delimitado los bloques mayores del pasado andino: Kroeber emprenderá el primer refinamiento de las cronologías relativas internas de estas grandes secciones, que nace precisamente del afán de clasificar el material publicado. Hacia 1930 su periodificación general comprendía cuatro segmentos: Periodo Temprano, Periodo Medio u Horizonte Epigonal-Tiahuanaco, Periodo Tardio, Periodo (u Horizonte) Inca. Esta clasificación que tenía como base el valle de Moche, permitía distinguir entre estilo y tiempo, y su utilidad hizo que se difundiera rápidamente. Curiosamente fue el propio Kroeber el primero en abandonarla en su último trabajo de síntesis (Rowe, 1959a: 3-4). En este libro, además de presentar su material y sus cronologías específicas, Kroeber (1944: 108) incluyó una sección conceptual, donde definía el estilo de horizonte (horizon style) como:

«[...] one showing definably distinct features some of which extended over a large area, so that its relations with other, more local styles serve to place these in relative time, according as the relations are of priority, consociation, or subsequence».

Paso seguido, Kroeber ubicaba los casos concretos. A los estilos de horizonte ya establecidos: Inca, Tiahuanaco (identificados por Uhle) y Chavín (por Tello), agregó el Negativo y —como posibilidadades - el Blanco sobre Rojo y el Nazca B-Y. Con base en estos marcadores estilístico-cronológicos elaboró un cuadro general más sofisticado (ver cuadro cronológico en Krober 1944: 112).

El tercer personaje de esta primera época es Julio C. Tello (1880-1947) quien en uno de sus primeros trabajos de síntesis propuso su Teoría andina de las tres épocas discutiendo lo que denominó Teoría de las importaciones culturales centroamericanas de Max Uhle. A Tello le interesaba resaltar el papel de la sierra en el proceso histórico andino. En tal sentido, indicó que antes que los pescadores costeños optaran por la agricultura, los pobladores de la selva ya habrían tenido ciertos cultivos, que luego difundieron a la sierra y finalmente al litoral. La civilización sería típicamente serrana, la costa, un área receptora de influencias. Las Tres grandes etapas o épocas derivadas de una misma cultura desarrollada en la sierra comenzaron con una Primera época megalítica o arcaica andina que, por el avance de su arte lítico y textil, habría durado más tiempo (10 siglos). Durante la Segunda época del desarrollo y diferenciación de las culturas del litoral, la civilización habría descendido a los llanos por las quebradas cisándinas, coexistiendo con las nuevas culturas Muchik y Nazca, derivadas de la arcaica andina (8 siglos). Finalmente, la Tercera época de las confederaciones tribales, se extendía hasta los incas (355 años) (Tello, 1929: 17-26). Posteriormente, el médico huarochirano ratificó su esquema, recalcando que mientras en la sierra se daba una especie de continuum cultural, los grandes yacimientos de la costa evidenciaban claras modificaciones (Tello, 1980 [1932]: 108). Los «troncos culturales» serranos se habrían propagado al litoral en sucesivos periodos. Las culturas de Chavín y Mantaro formaron el primer Horizonte o Estrato Inferior del Litoral. Las culturas de Cajamarca, Apurímac y Tiahuanaco unidas a las culturas locales formadas al impulso de las primeras constituyeron el Horizonte Medio. Junto con las culturas desarrolladas, la Inca formó el Estrato superior. Como corolario y sustento de su propuesta produjo un esquema, formalmente muy distinto a los anteriores, dividido en edades12 (ver cuadro cronológico en Tello, 1942 [1939]: lámina VII).

La comparación entre los tres cuadros precedentes permite observar una diferencia estructural: Uhle enfatizaba en la dinámica del proceso, Tello en la permanencia. El primero remarcó las subdivisiones, el segundo las soslayó (y confundió). Kroeber no es

12 Obviadas las descripciones laudatorias, no existe una exégesis de la obra de Tello. Para sus clasificaciones, hay una aproximación en Strong (1948: 93-94) y Roselló (1985). 
un punto medio, sino quién precisa e intensifica la ruta de pesquisa instaurada por Uhle, mientras trata de incorporar el caudal informativo obtenido por Tello, de cuyos criterios interpretativos difiere radicalmente (cf. Kroeber, 1942; 1944). Desde entonces, el término horizonte tiene significados opuestos. Para Uhle resulta de una unificación efímera, para Tello ratifica la unidad andina. Kroeber hace del estilo de horizonte una herramienta de trabajo, que le permitirá sintetizar la información existente y ratificar la trilogía clásica: Chavín, Tiahuanaco e Inca.

\section{CONSENSOS EVOLUCIONISTAS: LA MESA REDONDA DE CHICLÍN (1946), EL PROYECTO VIRÚ, Y SUS EPÍGONOS}

Concluida esta etapa fundacional de las periodificaciones arqueológicas, aparece una nueva generación de investigadores. En el caso peruano se trata de la segunda, en la que destaca el ingeniero Rafael Larco Hoyle (1901-1966), y para los extranjeros, de la tercera. La intersección de ambas se dará en la Mesa Redonda de Chiclín, promovida conjuntamente por los miembros del proyecto del valle del Virú del Institute of Andean Research y Larco Hoyle, en agosto de 1946. Aunque la convocatoria incluía a las principales autoridades nacionales (Jorge Muelle, Julio Tello y Luis Valcárcel), de los peruanos solo participó el anfitrión. En la primera jornada, los arqueólogos norteamericanos presentaron informes parciales sobre sus investigaciones: Junius Bird (Descubrimientos Precerámicos), Donald Collier (Culturas Post Mochica en el Virú), James Ford (Muestreo de Superficie), Gordon Willey (Patrones de Asentamiento en el Virú), Wendell Bennett (Grupo Gallinazo), William Strong (Secuencia Estratigráfica del Virú) y W. Mc Bryde (Aspectos Geográficos del Virú). $\mathrm{Al}$ día siguiente, basándose en sus estudios de campo y el abundante material depositado en el museo de su hacienda, Larco presentó su secuencia para la costa norte que - de acuerdo al testimonio de Willey (1946a: 132-134) — salvo en ligeros detalles, coincidía con el cuadro presentado por Strong para el Virú. Según el propio autor la secuencia que expuso comprendía siete épocas: Pre-cerámica, Inicial Cerámica, Evolutiva, Auge, Fusional, Imperial, Conquista (Larco, 1948: 10).

No era la primera vez que Larco planteaba su periodificación. En 1938 (pp. 36-49) había publicado una cronología de las culturas costeñas, que esbozaba siete épocas, pero apenas caracterizadas. En 1946 distinguió más detalladamente Cupisnique, Salinar y Mochica, sin hacer mayores conexiones evolutivas. La secuencia que presentó en la Mesa Redonda de Chiclín sería actualizada con las investigaciones de Bird en el sitio de Huaca Prieta, y presentada en el Congreso de Americanistas (1950). Posteriormente, su periodificación se mantendrá (comparar Larco, 1948 y 1963). Sus épocas estaban principalmente basadas en la cerámica como elemento diagnóstico y divididas en periodos (inicial, medio y último) para realizar una mejor explicación de la «evolución de las culturas». Así, por ejemplo —indicaba Larco- la época evolutiva (que a grandes rasgos correspondería con el formativo de Willey) se iniciaba con la cerámica hecha en molde, sin el felino estilizado como motivo decorativo. En el periodo medio de esta época, el motivo felínico se convertía en elemento diagnóstico básico. Finalmente, en el último, desaparecía, siendo reemplazado por dibujos geométricos incipientes, aplicados con brocha sobre la cerámica sin engobe (Larco, 1963: 18)13.

13 La coincidencia de resultados entre el proyecto Virú y los trabajos de Larco merece estudiarse en detalle. Strong (1948: 100) reconoció que el primero en trabajar con ese sistema de estadios fue el hacendado de Chiclín. Sobre la trascendencia de las clasificaciones de Larco, siempre se cita que el seminario dirigido por J. Rowe -en 1950 - comprobó su secuencia específica para el estilo moche (1948) contrastándola con el material excavado por Uhle en el sitio F (Anónimo, 1951). Sobre su vigencia ver Arsenault (1995: 460) y Castillo (2001). 
Conviene volver a la discusión principal de la Mesa Redonda de Chiclín, ya que estuvo centrada en la periodificación, específicamente en la contraposición entre criterios cronológicos y evolutivos. Se intentaba aclarar si las épocas eran periodos de historia simultáneos en los distintos valles o si eran estadios de desarrollo en los que la contemporaneidad era puramente fortuita. Fue entonces que Willey resumió el rasgo básico de la concepción temporal del proyecto Virú. Debido a las particularidades del área andina, se podía establecer una gruesa equivalencia:

«[...] si las Épocas fueron niveles básicamente horizontales en una trama temporal, la proximidad entre los centros culturales del Antiguo Perú permitía un rápido intercambio, y las tendencias de desarrollo afectaban a todos los centros casi simultáneamente. Así, las Épocas u horizontes temporales parecían corresponder con niveles generales de desarrollo cultural dentro de la intensiva área cultural peruana» (Willey, 1946a: 134).

Se concluyó que la prehistoria peruana podía ser segregada en épocas horizontales significativas (significant horizontal Epochs), de las cuales las principales se aproximarían a las siete ya citadas. Los asistentes al evento resolvieron que el procedimiento válido para definir cualquier epoca histórica horizontal (horizontal historical Epoch) sería determinar una especie de «mínimo común denominador» para todas las culturas pertenecientes a ese periodo 14 .

Pocos meses antes de realizar la conferencia de Chiclín (1946), el Institute of Andean Research había iniciado el Proyecto del valle del Virú. La investigación intensiva - y fugaz- en el mencionado valle permitió trazar un cuadro completo de su historia cultural, surgiendo así la primera secuencia referencial — de corte evolutivo — de la arqueología peruana15. El ajuste conceptual complementario a la mencionada reunión fue el Simposio de Nueva York (17-19 de julio de 1947) donde participaron básicamente los mismos estudiosos ${ }^{16}$. Se presentaron algunas herramientas conceptuales, como la «co-tradición» (Bennett) o una revisión de los «horizontes» (Willey), algunos resultados puntuales, y ensayos de clasificación evolutiva específica (Strong) y general (Steward). En un momento que se realizaban grandes síntesis sobre los sistemas económico-sociales a nivel mundial, la costa norte, y específicamente la secuencia del valle del Virú, se convirtió en el modelo para interpretar la historia de toda el área andina. La secuencia local quedó automáticamente ajustada a los parámetros de una nomenclatura universal 17 .

14 Al publicar su secuencia presentada en la Mesa de Chiclín, Larco (1948: 7) sostuvo una tesis semejante a la de Willey, que asociaba íntimamente el sistema de periodificación y la distribución espacial: «La relativa pequeña distancia que hay entre valle y valle, y entre la costa y sierra, centros de las principales culturas del Perú-, dio por resultado un rápido intercambio de elementos y un desarrollo casi uniforme de ellas. Esta característica permite, al hacer el cuadro sinóptico, dividir las épocas culturales peruanas en líneas horizontales ya que la propagación de estos elementos se llevó a cabo en muy corto tiempo».

15 Sobre el proyecto ver Willey (1946b; 1999). Respecto a su fugacidad, se ha indicado que durante la única campaña de 1946 se registraron más de 300 sitios. Según testimonios ulteriores del propio Willey, el inventario fue bastante incompleto: el valle contenía tres o cuatro veces más sitios arqueológicos. Ver Arsenault (1995: 446, n. 6).

16 Además de los miembros del proyecto Virú, presentaron ponencias M. Newman, G. Kubler, S. Lothrop, A. Kidder, J. Steward y J. Rowe, aunque este último no asistió. Larco no estuvo y Kroeber encabezó el encuentro (Bennett, comp., 1948). P. Armillas, se encargó de proyectar el esquema a la secuencia mexicana (cf. también Armillas, 1957).

17 Sobre la génesis de estas clasificaciones ver Strong (1948: 100-101). La continuación de esta línea en Collier (1960 [1955]) en el simposio mundial dirigido por Steward. 
Un acontecimiento bibliográfico inmediatamente previo al proyecto Virú fue la publicación del Handbook of South American Indians, dirigido por Julian Steward. En su segundo volumen (1946) — una gran síntesis de la historia andina - habían publicado prácticamente todos los participantes de la Mesa de Chiclín. Aún más voluminosas resultaron las consecuencias editoriales: de toda la serie de publicaciones, cabe detenerse en Andean Culture History (1949) de Bennett \& Bird, que consagra la proyección teórica del pequeño valle septentrional. Anteriormente Bennett (precisamente en el Handbook... 1946: 80) había planteado un esquema de síntesis, pero las marcadas diferencias respecto a la propuesta posterior dan cuenta de la impronta del mentado proyecto. La nueva periodificación insiste en el problema de distinguir entre lo cronológico (rasgos que permiten ubicar el material en un determinado momento) y lo evolutivo (rasgos que indican de qué tipo de sociedad se trata). Para organizar la información Bennett y Bird asumen dos tipos de horizontes: simples (caracterizados por un rasgo único, p.e. la cerámica o la textilería) y complejos (caracterizados por un conjunto de técnicas). Tales horizontes permitían sincronizar la información de distintos valles. Para situar cronológicamente las manifestaciones culturales de un valle bastaba con ubicar los horizontes (p.e. Inca o Tiahuanaco) y hacer comparaciones con la secuencia del Virú. La presencia de una serie de estilos horizontales en los Andes Centrales proporcionaba pruebas adicionales de su unidad cultural. El concepto de horizonte de estos arqueólogos norteamericanos contaba con un valor esencialmente homotaxial, cultural (ver cuadros cronológicos en Bennett \& Bird, 1949: 112; 1960: 82-83). Considerado lo anterior, estos autores esbozaron la periodificación que se convertiría en prototipo de la tendencia evolucionista. Es preciso resumirla como se ve en el cuadro de la página siguiente.

El enfoque evolucionista de Bennett y Bird aprovechaba aspectos estilísticos, como los horizontes, para organizar la información. A la trilogía básica (Chavín-Tiahuanaco-Inca) sumaban otros horizontes de referencia (Blanco sobre Rojo y Negro, Blanco y Rojo). A eso le agregaban la supuesta homogeneidad intrínseca del área andina (co-tradición) para justificar la generalización de los estadios. Este manual tuvo un éxito inmediato, e incluso epígonos, aunque no faltaron las críticas18. En 1956 Geoffrey Bushnell retomará el esquema, añadiendo el hipotético periodo de los Cazadores tempranos y denominando - a la mexicana- Clásico al de los Maestros Artesanos. Al año siguiente, Alden Mason —inspirándose también en Steward (1948) - combinará más aún el cuadro: Incipiente (Preagrícola y Agrícola temprano), de Desarrollo (Formativo, Cultista y Experimental), Floreciente y Culminante (Expansionista, Urbanista e Imperialista)19. Estas últimas fueron solo algunas de las diversas nomenclaturas propuestas, y contribuyeron a una mayor confusión. Se ha observado que estas periodificaciones revelan la principal dificultad de usar estadios como formas de organizar la información, ya que se debe asumir sincronía de eventos semejantes en un área amplia con — supuesta- homogeneidad secuencial. Incluso carecen de coherencia interna: antes que por usar términos enteramente subjetivos (v.g. clásico), por mezclar criterios (artísticos, económicos, etc.) en una misma secuencia. (Lanning, 1967: 23)

18 Más adelante se aludirá a las reseñas de Rowe (1949; 1950). En el prólogo a la segunda edición, Bird (1960: IX-XII) reconoce la pertinencia de estas críticas, específicamente de sus observaciones sobre periodificación. Aunque el contenido del libro apenas se modificó, el cuadro cronológico sufrió significativas alteraciones (comparar Bennett \& Bird 1949: 12; 1960: 82-83). La representación gráfica del horizonte adquirió el caracter de línea ligeramente inclinada que lo caracterizará por algunos años, se volvió a los tres horizontes, se enfatizó en la variabilidad entre zonas y se agregó la secuencia del norte chileno. Las observaciones de Kubler (1985 [1970]: 401) sobre tal libro van en idéntica dirección, y pueden resumirse en: «Such "stages" displayed an evolutionary circularity of method, whereby the desired conclusions are among the premises».

${ }^{19}$ Mason (1978 [1957]: 29-31) incluye una defensa de la tendencia de «desarrollo funcional», que permite entender la situación de la época. 


\begin{tabular}{|c|c|c|}
\hline Estadio & Cronología & Rasgos \\
\hline $\begin{array}{l}\text { Primeros } \\
\text { agricultores }\end{array}$ & $\begin{array}{l}3000(?) \\
-1000 \text { a. } \\
\text { C. }\end{array}$ & $\begin{array}{l}\text { En general costeños, sin cerámica. La información } \\
\text { esencialmente provenía de Huaca Prieta. Con Tello, } \\
\text { sostenían que aunque en la costa había evidencias } \\
\text { del inicio de la cerámica, se trataba de reflejos } \\
\text { serranos. }\end{array}$ \\
\hline Cultistas & $\begin{array}{c}1000 \text { a. C. } \\
-0\end{array}$ & $\begin{array}{l}\text { Florecimiento repentino y abrupto, presencia } \\
\text { de cerámica bien elaborada. Sin control agrícola } \\
\text { completo de los valles. Las manifestaciones del } \\
\text { motivo felínico sugieren un fuerte culto religioso y } \\
\text { permiten hablar de un horizonte chavín. }\end{array}$ \\
\hline Experimentadores & $0-600$ & $\begin{array}{l}\text { Escasamente vinculados al estadio previo, aunque } \\
\text { la cerámica utilitaria, no decorada, mostraría la } \\
\text { continuidad de población. Presencia del horizonte } \\
\text { Blanco sobre Rojo permitiría sincronizar las } \\
\text { manifestaciones culturales, aunque —a diferencia } \\
\text { del Chavín- no indicaba uniformidad cultural. }\end{array}$ \\
\hline $\begin{array}{l}\text { Maestros } \\
\text { artesanos }\end{array}$ & $600-1000$ & $\begin{array}{l}\text { Culminación tecnológica y artesanal, iniciada en } \\
\text { el periodo previo. Sin horizonte estilístico y con } \\
\text { profunda regionalización (Nazca, Moche). }\end{array}$ \\
\hline Expansionistas & $\begin{array}{c}1000 \\
-1200\end{array}$ & $\begin{array}{l}\text { Caracterizado por la conquista como forma de } \\
\text { dominio. Continuas guerras internas y desbarajuste } \\
\text { de los sistemas hidráulicos. Presencia del horizonte } \\
\text { Tiahuanaco (complejo: cerámica, textiles, lítico) } \\
\text { vinculado al fenómeno expansionista. Luego } \\
\text { aparecen estilos locales y en la costa norte el } \\
\text { horizonte Negro, Blanco y Rojo. }\end{array}$ \\
\hline $\begin{array}{l}\text { Constructores } \\
\text { de ciudades }\end{array}$ & $\begin{array}{c}1200 \\
-1450\end{array}$ & $\begin{array}{l}\text { Aparecen estilos locales que van más allá de lo } \\
\text { Tiahuanaco. En cada área principal hubo una } \\
\text { cultura. Caracterizado por la presencia de pueblos } \\
\text { planeados a gran escala. }\end{array}$ \\
\hline Imperialistas & $\begin{array}{c}1450 \\
-1532\end{array}$ & $\begin{array}{l}\text { Imperio político y horizonte complejo (cerámica, } \\
\text { arquitectura, técnicas, textilería, metalurgia). Se } \\
\text { complementa con información etnohistórica. }\end{array}$ \\
\hline
\end{tabular}

\section{SINCRONIZAR CONCEPTOS: LAS MESAS REDONDAS DE LIMA $(1953,1958,1959)$}

Es fácil imaginar la situación imperante a inicios de los cincuenta si ya una década antes, Kroeber (1944: 225-226) se quejaba de las disputas sobre nomenclatura. La Mesa Redonda sobre Terminología Arqueológica realizada en enero de 1953 estuvo dedicada a afrontar estas dificultades. Participaron especialistas nacionales (Jorge Muelle, Toribio Mejía, Augusto Soriano, Luis Valcárcel) y estadounidenses (Richard Schaedel, Louis Stumer, William Strong). 
Luego de esbozar una «Teoría de sistemas de clasificación», propusieron una serie de términos aplicables a las culturas de la costa y la sierra. La discusión se basó en los sistemas de Julio Tello (Tres Épocas) y Rafael Larco (Siete Épocas), considerando especialmente lo resuelto en Chiclín (1946). Para denominar las culturas se recurrió a dos criterios: étnico y sitio tipo. En caso de contar con evidencia histórica (p.e. crónicas) se aplicaba el primero y se utilizó en los grupos culturales posteriores a la influencia tiahuanacoide. El segundo servía en todos los demás casos y podía ser tanto el primer sitio donde se había identificado la cultura como donde se le encontraba exclusivamente (Varios, 1953). Con base en ambos criterios, se eliminó más de medio centenar de nombres de sitios y estilos costeños: 24 del norte, 23 del norcentro y 10 del sur. Eran patentes los problemas provocados por las periodificaciones apresuradas. Durante las sesiones de discusión, Muelle advirtió:

«Los términos arcaico y clásico son alusivos a estilos artísticos. Cuando los empleamos estamos aludiendo a una clasificación del material, debemos desterrarlos de la clasificación de la cultura». (Varios, 1953: 9)

«Cuando decimos Chavín clásico no [nos] estamos refiriendo a la clasificación político-económica sino al estilo». (Varios, 1953: 12)

Se adoptó dos sistemas paralelos: uno de criterio económico (Pre-agrícola, Agrícola Incipiente y Agrícola) y otro sociopolítico (Formativo, Florecimiento Regional, Gran Fusión, Reinos y Confederaciones, e Imperio). Aunque todavía muy condicionada por la información norcosteña, esta reunión permitió establecer una terminología uniforme. Desde entonces, las convenciones establecidas sirvieron de referencia para los informes de excavación, tanto en la denominación de los estilos como en la nomenclatura de las divisiones temporales 20 .

1958 fue un año especialmente significativo para la periodificación. En Estados Unidos, se publicó Method and Theory in American Archaeology, y en Lima se realizaron dos encuentros sobre terminología arqueológica. El libro de Willey \& Phillips (1970 [1958]) era un manual para la clasificación cultural, que incluía desde la definición de conceptos operativos hasta la proposición de una clasificación evolutiva continental. En la primera sección se plantea la diferencia entre horizonte y estilo de horizonte, considerando este último como una vía de acceso al primero, que debía ser más ampliamante definido. Caracterizaron al horizonte como «a primarily spatial continuity represented by cultural traits and assemblages whose nature and mode of occurrence permit the assumption of a broad and rapid spread», agregando que las unidades arqueológicas vinculadas por el horizonte eran solo apróximadamente contemporáneas (Willey \& Phillips, 1970 [1958]: 33). En la sección dedicada a la síntesis cultural proponían los siguientes estadios: Lítico, Arcaico, Formativo, Clásico y Postclásico. El Lítico correspondía a los orígenes del poblamiento americano, el Arcaico a los cazadores, recolectores y pescadores del Holoceno, sin conocimiento de la cerámica, y teóricamente de la agricultura. El Formativo estaba conformado por los primeros grupos agricultores, generalmente poseedores de cerámica y el Clásico se vinculaba a la edificación de centros urbanos. Finalmente, el Post-Clásico aludía a los estados militaristas. Los primeros tres estadios se detectaban en toda América, los dos últimos solo en los Andes y Mesoamérica21.

\footnotetext{
20 Ver el cuadro de Stumer, 1954 (en Valcárcel, 1967); Tabío, 1965: 27, inter alia.

21 Ya que este esquema ha sido tan usado como criticado, vale indicar que sus denominaciones corresponden a distintos criterios: el primer estadio fue definido por un tipo de material (Lítico), otros por un criterio económico (Formativo, caracterizado por la agricultura), mientras el Arcaico no pasó de ser un segmento artificial, sin atributos propios (Prous, 1992: 108-111).
} 
En enero del mismo año se realizaba en Lima un evento de signo opuesto: la Mesa Redonda de Ciencias Antropológicas (Varios, 1958). Fue entonces que Jorge Muelle, Eugene Hammel y Edward Lanning disertaron Sobre el concepto de horizonte en la arqueología peruana. En franca distancia con tendencias anteriores, calificaban a las secuencias evolucionistas apresuradas como «meta-arqueología». Como elemento ordenador para las clasificaciones proponían una redefinición del horizonte. Advertían que no se trataba de un fenómeno plenamente simultáneo, dado que era muy difícil la difusión instantánea de un estilo. El horizonte, podría representarse como una línea ligeramente inclinada. En sus términos,

«Horizonte es el plano imaginario que conecta un segmento dado de una columna estratigráfica con el segmento análogo de otras columnas en el esquema clasificatorio. La conexión se hace por la identificación de un mismo complejo morfológico» (Muelle et al., 1958: 73)22

Aunque la historia de este encuentro está apenas documentada, hay indicios de que entre las decisiones finales, se reconoció como marco organizativo básico, el cuadro cronológico de John Rowe, entonces denominado esquema «tempo-espacial»23.

En agosto de 1958, se efectuó la Mesa Redonda de Terminología Arqueológica en el marco del Segundo Congreso Nacional de Historia24. La ponencia principal estuvo a cargo de Richard Schaedel quien resumió las conclusiones de la Mesa de 1953 y defendió su vigencia. Para este arqueólogo norteamericano, el sistema de estadios (Steward, Strong, Willey) era indispensable para la comparación transcultural. Para la nominación de sitios insistió en aplicar los criterios ya acordados y en la necesidad de conciliar entre «subdivididores» (principalmente norteamericanos) y «sintetizadores» (mayormente peruanos). En seguida, se pasó a discutir la aplicabilidad de la nomenclatura evolutiva anteriormente aprobada. Si bien hubo diversas observaciones puntuales, la crítica más insistente fue de un alumno de Jorge Muelle: Luis Lumbreras. Resaltó la dificultad de utilizar el sistema sustentado por Schaedel para la Sierra Central, donde el orden de los estadios era distinto, y defendió la utilidad de la propuesta «tempo-espacial» de Rowe. Finalmente se aprobó una modificación específica en la nomenclatura (reemplazar el término Florecimiento por Configuración). Sin embargo, lo más significativo - ya que preludiaba posteriores debates - resultó el contrapunto Schaedel/Lumbreras defendiendo la secuencia evolutiva y el sistema de Horizontes e Intermedios, respectivamente (Varios, 1959: 30-34)25.

La evidente brecha entre ambas tendencias encontró un escenario idóneo en la Semana de Arqueología Peruana organizada por la Universidad Nacional Mayor de San Marcos en noviembre de 1959. En este hito académico perduraba la búsqueda de conceptos

22 Estos complejos morfológicos eran definidos como el grupo de rasgos típicos asociados.

23 Según Valcárcel (1967: 56), el cuadro de Rowe (Peruvian Archaeology, Chronological Chart) fue impreso a mimeógrafo en 1955 para uso de los especialistas, y lo reproduce en el anexo de su libro. Bien visto, todavía no es radicalmente «horizontal», sino coincidente con la definición de Muelle, Lanning y Hammel. La referencia a la oficialización del cuadro en la Mesa de enero (1958) en las actas del evento siguiente (Varios, 1959: 31,33, 207). En su ponencia, Muelle, Hammel y Lanning (1958) respaldan explícitamente el esquema de Rowe, de quien — los dos últimos - eran alumnos en la Universidad de California. No he ubicado las actas tal como las cita Ravines (1994: 596, alusión a Matos, 1958). Agradezco a Hernán Amat por facilitarme una copia de las actas a mimeógrafo.

${ }^{24}$ Las actas de la Mesa consignan la participación oral de: J. Castro, T. Catanzaro, B. Flornoy, G. Fuentes, L. Lumbreras, J. Matos, T. Mejía, O. Nuñez, A. Rossell, R. Schaedel, L. Stumer, P. Villar (Varios, 1959: 30-34).

25 Además de invocar la pertinencia de la propuesta de Rowe, Lumbreras la usó en el cuadro sinóptico de su ponencia (Varios, 1959: 226). Lo mismo hicieron otros dos miembros de la nueva generación de arqueólogos peruanos (Duccio Bonavia y Ramiro Matos) (Varios, 1959: 167, 207). 
sistematizadores (no necesariamente evolutivos) para la arqueología andina. Lo marcante en tal sentido fue la ponencia de Rowe. Si bien su propuesta general ya se estaba difundiendo indirectamente, este arqueólogo norteamericano presentó entonces un ejemplo práctico de su metodología: explicó la seriación por semejanza del estilo nasca, realizada en colaboración con Lawrence Dawson. No se trataba ya de los «descubrimientos de sitios» o de las «secuencias regionales» de incógnito fundamento. Luego del recuento analítico de las clasificaciones previas de este estilo, Rowe planteaba una solución, es decir una secuencia cronológica relativa. Sin embargo, lo más novedoso era que explicaba su lógica interna. Esta secuencia se concatenaba a una mayor que estaban elaborando para el valle de Ica. En suma, la ponencia era el indicio de una tendencia, de una escuela. Sin embargo, el evento no fue unísono: permitió confrontar una nueva versión de la propuesta de los estadios (Choy) y la incipiente secuencia maestra (Rowe)26.

\section{EL HORIZONTE REDEFINIDO, DESDE ICA}

Aunque la propuesta teórica consolidada de John Rowe debe fecharse en 1962, su aproximación documentada al tema podría remontarse a sus primeros ensayos de datación absoluta a partir de fuentes históricas $(1945 ; 1948)$. Sus críticas a la tendencia evolutiva son inmediatas al proyecto Virú: aparecen bajo la forma de dos reseñas $(1949 ; 1950)$ al libro de Bennett \& Bird (1949). Su puntería estuvo dirigida a la periodificación, mejor dicho, a desmontar el cuadro sinóptico de sus colegas. Cuestionaba la extrapolación de la secuencia del Virú a los Andes, mostraba puntualmente como esta no se cumplía - especialmente en el sur andino - e indicaba una serie de contradicciones en el propio texto debidas a la impuesta homotaxialidad. Como solución para la síntesis, Rowe sugería la presentación de la secuencia nor-costeña, indicando sus diferencias con las — básicamente paralelas - de la sierra norte y la costa central, pasando luego a describir las secuencias — muy distintas — de la costa sur y Tiahuanaco. El impacto de esta reseña fue inmediato, sus consecuencias paulatinas27.

En los diversos artículos de este arqueólogo norteamericano resulta evidente su distancia conceptual frente a la corriente imperante, que no se limita a la periodificación, sino que implica su complemento, el espacio (la definición de área cultural) y —en general— su percepción del pasado. En 1952 Rowe había iniciado con Dawson el mencionado proyecto de seriación de la cerámica paracas y nazca, al que luego se uniría Dorothy Menzel. En colaboración con otros especialistas - también de la Universidad de California (Berkeley) — viajarían recurrentemente a Ica para realizar estudios intensivos: desde el precerámico hasta la época colonial28. Esto le permitió trabajar en dos frentes. El específico, planteando una nueva cronología relativa del material cerámico de Ica. Para elaborar la secuencia del estilo nasca se utilizó como base colecciones de museos. La definición de las

26 La edición de las actas estuvo a cargo de R. Matos (1960). La referencia al roce conceptual Choy-Rowe en el epílogo de Muelle (397).

27 Hubo una rápida reacción de Willey (1951). Al responder, Rowe (1951) insistirá en su crítica a la co-tradición de Bennett inspirada en los hallazgos del Virú y en la propuesta de Kroeber. En el mismo sentido iba su cuestionamiento al concepto de área-cultural usado por George Murdock en su libro sobre etnias sudamericanas (Rowe, 1953). En la segunda edición de Bennett \& Bird (1960) es patente el interés por atender a las observaciones de Rowe, especialmente en el cuadro cronológico, que resultó más complejo (ver nota 18).

28 Una caracterización de la obra de Rowe en Menzel (1969), Hammel (1969) y Patterson (1989: 49-50). La descripción del proyecto en Rowe (1956; 1970 [1961]) y Menzel (1960; 1971 [1961]). 
fases se sustentó en asociaciones funerarias y en fragmentos hallados en sitios domésticos. Identificados los extremos del estilo (Paracas y Huari), el método de clasificar fue la seriación por parecido, que no asumía a priori la dirección del cambio estilístico, como sí lo habían hecho sus colegas anteriores29. Establecida la secuencia preliminar, se le contrastó con las excavaciones más recientes y con 7 fechados radiocarbónicos. El resultado fue una secuencia de 9 fases (Rowe, 1960b). Para seriar el material paracas se aplicó un modelo semejante. Luego de diversos ajustes, la clasificación preliminar de 4 fases desembocaría en una más refinada -y corregida- de 10 (Rowe, 1957; Menzel et al., 1964)30. Los periodos posteriores de la misma secuencia (del Horizonte Medio al Horizonte Tardío) fueron sistematizados por Menzel (1964; 1971 [1961]; 1976, inter alia). La labor realizada en esta región fue complementada por trabajos paralelos, como la tesis de Edward Lanning (1960) que sirvió para definir el Periodo Inicial y la de Thomas Patterson (1966) sobre el Intermedio Temprano en la costa central.

En el ámbito general, Rowe (1960a [1959]; 1962) reformuló el sistema de referencia cronológica de toda el área andina31. A fin de evitar las dificultades presentadas por los estadios, propuso usar periodos para organizar la información arqueológica. Según su redefinición, estos no aludían a características culturales, servían como mera referencia cronológica — relativa - para organizar el material arqueológico. De este modo se podrían realizar distinciones claras entre estilo y tiempo, trama de la interpretación del proceso cultural32. La base comparativa sería la secuencia maestra de lca, de inusitada minuciosidad, vinculable a otras áreas por criterios de contemporaneidad absoluta y relativa33. De acuerdo al método de seriación, se asumían los rasgos diagnósticos de la cerámica de esta zona como pauta para establecer una secuencia referencial para clasificar el material del área andina. Consecuentemente, se propuso:

- Horizonte Tardío

- Intermedio Tardío

- Horizonte Medio

- Intermedio Temprano

- Horizonte Temprano

- Periodo Inicial

Así, el Horizonte Temprano se iniciaba cuando las influencias estilísticas chavín se percibían en el valle de Ica. En la misma forma el Horizonte Tardío comenzaba con las primeras evidencias inca en el mencionado valle y no con la emergencia del estado inca en su área de origen. Esta periodificación se restringía a lo cronológico —o mejor dicho, reconocía su valor como paso previo imprescindible- de modo que los horizontes no significaban la generalización de patrones culturales (como en la definición de Kroeber o Willey) sino solo

29 La explicación del método de seriación por parecido en Rowe (1959b; 1961).

30 La piedra angular de la secuencia (1964) fue reseñada por Lathrap (1966).

31 Ya que la propuesta de Rowe muestra variaciones, solo se aludirá a su versión definitiva (1962). Estas modificaciones se evidencian al comparar el mencionado cuadro de 1955 (en Valcárcel, 1967) y el cuadro enteramente «horizontal» de 1958 (Rowe, 1960a [1959]: 16). La diferencia se explica a partir de la concepción de la secuencia maestra.

32 Rowe (1959a: 3-5) alude a los antecedentes de su propuesta: tanto Alfred Kroeber como James Ford habían esbozado sistemas de clasificación parcialmente semejantes, pero los abandonaron.

33 La primera secuencia maestra fue presentada en Menzel (1971 [1961]). Una versión corregida y correlacionada a otras áreas aparece en Rowe \& Menzel (1967: 2-3). Los criterios de contemporaneidad en Rowe, 1962: $49-50$ y —en la misma línea- Patterson, 1963. 
contemporaneidad, para lo cual se proponía una serie de formas de reconocimiento. Más citado que aplicado, desde fines de los cincuenta, el esquema de Rowe se convirtió en el armazón de las diversas investigaciones de arqueología peruana.

El alcance de los cambios producidos por esta escuela puede calibrarse considerando que no solo se trató de modificar la zona (del Virú a Ica) sino el concepto de referencia (de una secuencia homotaxial a una secuencia maestra). No fue únicamente una reformulación teórica del método de clasificación (de la tipología a la seriación por parecido, de lo cuantitativo a lo cualitativo) sino de su aplicación y contrastación intensiva durante aproximadamente dos décadas. Se buscó anular todo sesgo evolucionista que interfiriese el proceso de periodificación/clasificación cultural. En suma, de una forma distinta de formalizar/concebir el pasado.

\section{EL REFLUJO DE LOS ESTADIOS}

Corresponde a Emilio Choy (1915-1976) haber reorientado las propuestas evolucionistas. En su artículo de síntesis sobre La revolución neolítica en los orígenes de la civilización americana, presentado en la Semana de Arqueología de 1959, proponía dos clasificaciones. Primero, para el material de la costa norte (valles de Moche, Chicama, Virú) alude al Salvajismo (o Paleolítico), al Neolítico (que incluye Barbarie Inferior, Media y Superior) y a la Civilización, que se iniciaría con Mochica II y Gallinazo II. Su segunda propuesta abarcaba toda el área andina e incluía: Paleolítico, Mesolítico, Neolítico (o Agricultura Incipiente), División de Clases, Reyes Sacerdotales, Estado y Monarquías Confederativas (1960: 196-198). Antes que incorporar información inédita, Choy esbozo una explicación articulada del proceso. Los artículos de este autodidacta chalaco $(1960,1987$ [1967], 1969) evidenciaban un uso del trabajo del arqueólogo australiano Gordon Childe para releer el material recopilado por el proyecto Virú34. Choy no llegó a desarrollar su propuesta, imbricándola detalladamente con material arqueológico. Tal labor quedaría en manos de otro participante de la Semana de Arqueología (1959).

Luego de algunos trabajos menores, en el artículo Acerca del desarrollo cultural en los Andes expuesto en la Mesa Redonda de Ciencias Prehistóricas y Antropológicas (13-18 de octubre de 1965), Lumbreras (1969a) esbozó una síntesis general. Propuso una división regional de los Andes y definió los «periodos» correspondientes para el Área Central: Lítico, Arcaico (temprano, medio, tardío), Formativo (inferior, medio, superior), Desarrollos Regionales, Expansión Wari, Estados Regionales e Imperio del Tawantinsuyo. Mientras los tres primeros se vinculaban a la propuesta de Willey \& Phillips (1970 [1958]), descartaba el uso de los términos Clásico y Post-clásico, para recurrir a una denominación que incidiera en los rasgos locales. Complementariamente, (1969a: 150-152) propuso los siguientes segmentos evolutivos para toda el área andina: Estadio de los Recolectores, Estadio de los Agricultores Aldeanos (Arcaico, Formativo, Culturas Regionales) y Estadio de la Civilización.

El arqueólogo ayacuchano afirmaba que no era preciso contraponer periodos y estadios, dado que se les podía utilizar complementariamente. Sin embargo, en un giro total, arremetía ahora contra lo que consideraba «exceso antievolucionista» de Rowe, que lo habría llevado a variar el contenido de conceptos tales como el de «horizonte»:

\footnotetext{
34 Aunque nunca se menciona, Rowe (1962: 46-47) también usó —aunque de otro modo- las propuestas de
} Childe. La conexión Childe-Choy ha sido enfatizada por Flannery (1994). 
«[...] fijándole no el sentido homotaxial que tenía desde su incorporación a la Arqueología andina, sino un tratamiento arbitrariamente "horizontal", consistente en una línea de tiempo relativo que Rowe fija a partir de una columna de tiempo relativo que él y sus alumnos han establecido por métodos estilísticos en una región de los Andes (Ica)» (Lumbreras, 1969a: 149)

Para Lumbreras (1969a: 149), Rowe había «destruido totalmente la utilidad instrumental del concepto» horizonte. En tal sentido, describe una aparente paradoja: el periodo inca, denominado «Horizonte tardío», comenzaba, según Rowe, en 1476 de nuestra era, dado que el estilo Tacaraca $A$ coincidía temporalmente con el inicio de la ocupación inca del valle de Ica. Sin embargo, la época inca de Ayacucho, cuya conquista antecedió a la de Ica, quedaría en el Intermedio Tardío y la última parte de Chimú se incluiría en el Horizonte Tardío ya que su conquista fue posterior. Como los participantes de la Mesa Redonda de Chiclín (1946), Lumbreras unificaba criterios evolutivos y cronológicos para el área central andina ${ }^{35}$. Su propuesta definitiva apareció en De los Pueblos, de las culturas...(1969b) donde reconocía tres grandes estadios: Recolectores: Lítico (15000-3000 a.C.), Arcaico (40001200 a.C.); Agricultores Aldeanos: Formativo (1200 a.C.-100 d.C.), Desarrollos Regionales (100-800 d.C.); Industriales Urbanos: Viejo Imperio (800-1200 d.C.), Estados Regionales (1200-1470 d.C.), Imperio Tawantinsuyo (1430-1532 d.C.) (ver cuadro cronológico en Lumbreras, 1969b: 28).

\section{6. ¿UUN NUEVO CONSENSO?}

Aunque con una extraña fortuna crítica, el libro decisivo para la disciplina $-\mathrm{y}$ no solo en lo concerniente a la periodificación- había aparecido dos años antes. En Peru before the Incas, el arqueólogo norteamericano Edward Lanning (1930-1985) replanteó el sistema clasificatorio, proponiendo una fluida síntesis 36 . Entre las décadas de los cincuenta y sesenta, sus investigaciones en la costa, principalmente central, le habían permitido el conocimiento detallado del Periodo Inicial y del Precerámico.

Lanning organizó su manual aplicando las herramientas conceptuales presentadas por Rowe en sus artículos sobre periodificación, jerarquía de asentamientos y sistema de clasificación de sitios. Reconoció tres estadios generales, evidenciados por el material arqueológico: el Precerámico, el Inicial y el Cerámico. Para el último asumió la propuesta de su maestro y subdividió el primero en seis segmentos (Precerámico I al VI) con base en los trabajos realizados en colaboración con Patterson. Mientras los diversos horizontes e intermedios eran, por definición, simultáneos en toda el área andina central, el Periodo Inicial comenzaba en diversos momentos, dado que era el único plenamente determinado por un evento cultural: la introducción de la producción alfarera. Para evitar las dificultades

35 Un temprano cuestionamiento a los planteamientos de Lumbreras, en Macera (1968). Una crítica al carácter híbrido de su esquema de periodificación, en Browman (1976:191), Burger (1988: 110) y —además a su carencia de fundamentos cronológicos— en Paul (1991: 9).

36 Las valiosas observaciones críticas de Fung (1969) se restringen a la primera parte (el Precerámico y el Periodo Inicial) y no afectan en modo alguno el aspecto aquí destacado del texto. Lathrap (1969) lista una serie de errores puntuales, pero lo reconoce como el mejor trabajo general, e incluso vaticina su proyección futura. Critica su «costa-centrismo», en contraste con el «Virú-centrismo» de los libros anteriores. En la necrología de Lanning, Bonavia \& Matos (1985: 348) destacan los méritos del libro comentado. Patterson (1989: 51-53), condiscípulo de Lanning, dedica varias páginas a explicar el carácter innovador de su obra y específicamente de su trabajo de síntesis. Todos coinciden en afirmar el quiebre que significó este autor para la arqueología peruana, tanto en la extensión del corpus empírico como en su sistematización teórica. 
acarreadas por la adopción de estadios demasiado rígidos, Lanning escoge ciertos rasgos diagnóstico/comparativos para explicar el proceso: Primeros Habitantes, Aldeas y Templos, Inicios de la Cerámica, Culto Chavín, Surgimiento de Ciudades, Primer Imperio, etc. De modo que, aprovechando la sistematización cronológica, podía incidir en la variabilidad cultural. Esto le permitió articular espacio, tiempo y sociedad, en un cuadro que imbrica - aún hoy - la mayor cantidad de secuencias locales (ver cuadro cronológico en Lanning 1967: 26-27).

Con la propuesta Rowe-Lanning (1962/1967) quedaron planteados los límites lógicos en los cuales se mueve aún la periodificación de la arqueología andina. Lanning es el primero que hace lo que actualmente se considera imprescindible en un trabajo de generalización. ¿Cómo se puede probar esto? A modo de ejemplo ilustrativo, cabe aludir a la periodificación propuesta por el historiador Pablo Macera (1978). Este autor parte por reconocer que en el territorio hoy denominado Perú, se dieron diferentes historias e indica que es posible proceder a su división cronológica. Como criterio de la periodificación manifiesta haber utilizado las relaciones de poder político y económico. Así, dentro de la época denominada Autonomía incluye: Primeras Sociedades Preclasistas (recolectores, cazadores, pescadores); Primeros Horticultores y Pastores; Formativos Andinos; Primeras Diversificaciones Regionales; Horizonte Medio (La expansión wari. Proceso de urbanización); Segunda Diversificación (los señoríos regionales) y Horizonte Tardío (incluida la expansión imperial inca). Pese a insistir — acertadamente - en los plurales (Formativos, Diversificaciones) e indicar que el horizonte chavín y el estadio Formativo, son entidades distintas, no sucede lo mismo con los periodos posteriores, ni — en general — con la estructura de su sistema de clasificación. Este valioso ensayo no incluye una clara distinción entre criterios evolutivos y cronológicos, por lo que el conjunto — simple y llanamente- no cuaja.

El caso palmario de la vigencia del esquema Rowe-Lanning aparece entre los resultados del evento Críticas y perspectivas de la Arqueología Andina (Paracas, 1979). En este coloquio, Michael Moseley recapituló las incongruencias terminológicas precedentes. Indicó que al hacer periodificaciones se había incidido en términos basados en: Desarrollo (lítico, precerámico, formativo, etc.); Períodos (temprano, intermedio, etc.) y Expansión de sitios o estilos arqueológicos (imperio wari, expansión tiahuanaco, etc.) (Lumbreras, 1981: 22). El detalle más signficativo fue el (nuevo) cambio experimentado por Lumbreras: luego de sus incisivas críticas (1969a), acababa recomendando el esquema Rowe-Lanning (!). Aceptada la dificultad de aplicar categorías evolutivas para toda el área andina, Lumbreras (1981: 22-24) planteaba usar la secuencia maestra, considerando que se trataba de criterios puramente cronológicos. Para explicar el pasado andino, sugería categorías comparativas como las usadas por Childe para el Viejo Mundo (orígenes de la agricultura, de la cerámica, de la formación urbana y del estado, etc.). Solo la adopción de criterios coherentes de clasificación evitaría una homogenización por decreto. Si en lo primero el modelo explícito era Rowe (1962), en esto último la referencia (tácita) era Lanning (1967)37.

\section{EPÍLOGO: LOS LÍMITES LÓGICOS DE LA SECUENCIA MAESTRA}

Desbrozado el panorama, quedan dos puntos por resolver: ¿qué críticas (serias) se han planteado al modelo Rowe-Lanning? y icómo han procedido los periodificadores más recientes? Es preciso comenzar por el final.

37 Más aún: una década antes, Gordon Willey (1971, II: 82) había dado un giro análogo. En su manual de arqueología sudamericana, asumía el sistema Rowe-Lanning para organizar la información sobre Perú. Poco después, Rowe (1975) cuestionará incluso el esquema de Willey (y Sabloff) para periodificar la historia de la arqueología. 
Dentro del conjunto de textos dedicados a sintetizar el pasado prehispánico aparecidos en la década de los noventa, resulta pertinente referirse a cuatro casos muy distintos entre sí, a fin de ofrecer un panorama representativo: Duccio Bonavia (1991), Michael Moseley (1992), Daniel Morales (1993) y Peter Kaulicke (1994)38. En términos generales, Bonavia y Moseley coinciden en reconocer la utilidad del esquema Rowe-Lanning como elemento organizativo, aunque ambos realizan ciertas atingencias. En la senda de Lanning (1967), Bonavia propone un «esquema de desarrollo cultural» que acompaña a la columna cronológica ya establecida:

- Cazadores

- Recolectores

- De la caza a la agricultura (domesticación de plantas y animales, del villorrío al centro monumental)

- Primeras sociedades organizadas

- Culturas locales y regionales

- Primeros imperios andinos

- Renacimiento de las culturas locales y regionales

- Imperio incaico39

Por su parte Moseley hace breves observaciones sobre el fundamento de su periodificación y divide su texto basándose en la secuencia maestra. En ambos libros resulta patente la dificultad de lidiar con la sección anterior a la alfarería para la que no se cuenta con un adecuado sistema de periodificación. Sintomáticamente, en su cuadro cronológico Bonavia recurre a la propuesta de Lanning (seis periodos precerámicos) que él mismo había demolido en páginas anteriores (Bonavia, 1991: 107-108). Por su parte, Moseley divide esta sección en Lítico y Precerámico, basándose en cambios climáticos (!) (Moseley, 2001 [1992]: 107).

En los manuales de Morales y Kaulicke hay una posición totalmente distinta, y - significativamente- ninguno incluye cuadros cronológicos que resuman sus propuestas. En su libro, Morales (1993) mezcla los términos evolutivos y los propuestos por Rowe. Luego de referirse al Lítico, Arcaico (o Mesolítico andino) y Formativo pasa al Intermedio Temprano, Horizonte Medio e Intermedio Tardío. Esto provoca una serie de problemas, en la presentación de la información, pero sobre todo en la estructura interpretativa general, que anteriormente han sido evaluados en detalle (Ramón, 1994). La documentada síntesis de Kaulicke tiene un espectro temporal más preciso, pero procede de modo análogo 40 . El libro se dividide en Lítico, Arcaico y Formativo. Considerando que se trata del caso más elaborado de esta tendencia, conviene detenerse en su última sección. El autor justifica la elección del término Formativo «[...] por conveniencia ya que es de uso más frecuente por un gran número de arqueólogos nacionales y extranjeros» (1994: 259). Y, paralelamente, cuestiona el sistema de Rowe:

«El término "Horizonte", en cambio, se presta a malentendidos ya que depende directamente de la precisión tanto cronológica como estilística de lo que se entiende por el estilo Chavín». (1994: 547)

\footnotetext{
38 La segunda edición de Moseley (2001) no incluye modificaciones sobre periodificación. El conjunto de manuales podría complementarse aludiendo a los textos de Morris \& Von Hagen (1993), Ravines (1994), Richardson III (1994), Stone-Miller (1995), Silva (2000), y a los textos colectivos dirigidos por Keatinge (1988) y Lumbreras (1999). No se hace por falta de espacio y ya que no se ha ubicado novedades en el tema de periodificación.

39 Estos son los títulos de la subdivisión del cuadro final. La organización del indice (y del libro) es básicamente la misma.

40 El texto ha sido reseñado por Dillehay (1996).
} 
Kaulicke incluso propone una periodificación parcialmente modificada de aquel estadio. Una de las «novedades» consiste en conceder al término Formativo un valor meramente cronológico y subdividirlo en secciones menores con las fechas respectivas: Temprano (1500-1000 a.C.), Medio (1000-600a.C.), Tardío (600-400a.C), Final (400-200a.C) y Epiformativo (200a.C.-100/200 d.C.)41. Según el autor «El término Formativo se emplea aquí sin connotaciones evolucionistas con el afán de simplificar la terminología ya que tiene un uso generalizado en la mayoría de los países latinoamericanos» (?) (Kaulicke, 1994: 547).

Esta incorporación terminológica va precedida de una revisión histórica del término, por lo cual sorprende el resultado. Por definición, el Formativo es un estadio, es decir una categoría evolutiva: quitarle «sus connotaciones evolucionistas» es simplemente mutilarlo. Esto es paradójicamente equivalente a usar un periodo como marcador evolutivo y sostener que se le ha retirado el «componente cronológico»42. De todo esto, resultan dos corolarios. Primero, al dividir el Formativo cronológicamente (Temprano, Medio, etc.) y atribuirle fechas se le convierte en un recipiente temporal. Sin embargo, cada una de las subdivisiones de este redefinido Formativo mantiene rasgos culturales propios (descritos por el autor a lo largo del libro) como — por ejemplo— que el Medio sea considerado como la «edad clásica» (Kaulicke, 1994: 554; 1998: 12). Cada sección resulta un estadio generalizado, retornando al problema del proyecto Virú. Segundo, si este Formativo retocado solo marca tiempo ¿por qué no utilizar las categorías ya existentes? precisamente podadas de connotaciones evolutivas, mejor definidas, y que además resultan muy parecidas en términos cronológicos (v.g. el Formativo Temprano corresponde apróximadamente al Periodo Inicial; y el Formativo Medio, Tardío y Final al Horizonte Temprano). Pese a todas las críticas realizadas a los especialistas centrados en la seriación alfarera, lo que definitivamente (sin aludir a las «excepciones») divide Arcaico y Formativo es la presencia de cerámica, lo que equivale al concepto de Precerámico-Periodo Inicial. Incluso esto último es más flexible, ya que se trata de un rango y no de una fecha exacta 43.

Lo curioso es que luego de realizar críticas razonables a las propuestas/secuencias anteriores, el autor vuelve a tomar como base de referencia una suerte de combinación opaca de secuencias cerámicas específicas (las excavaciones de la «Misión japonesa» en la sierra norte) para proyectar sus subdivisiones cronológico-estilísticas convirtiéndolas en secciones estadiales (Kaulicke, 1994: 277, 284, 547). Más aún —como ya se ha indicadoesta innovación carece de efecto práctico ya que la subdivisión es virtualmente la misma. Obviamente esta serie de incongruencias se trasluce en los detalles44.

41 Además de este grupo de fechas (547) el autor incluye otras ligeramente distintas (284).

42 El entrampe lógico de este procedimiento también ha sido advertido por Silverman (1996: 104).

43 Con «excepciones» se alude a casos tipo «Formativo sin cerámica» lo que significa haber hallado sitios en los que pese a incluir rasgos culturales propios de la definición teórica de Formativo, no se han identificado tiestos. Esto no solo muestra que se sigue tratando de un estadio sino que continúa siendo «cerámico-céntrico». Cabe distinguir que si Lumbreras (1969b: 76-78) utiliza la aparición de la cerámica para caracterizar su Arcaico tardío, Kaulicke (1994) la hace coincidir con el inicio de su Formativo.

44 Un buen ejemplo de la difusión de esta tendencia y de las dificultades de adoptar un estadio como marcador cronológico son las actas del coloquio sobre el Formativo (Kaulicke, ed., 1998). En esta compilación, el Formativo es una subdivisión cronológica (aunque prácticamente cada participante le da límites temporales distintos) pero que presenta características curiosamente semejantes, ergo es un estadio. Una explicación (y aplicación) de la propuesta de Kaulicke (1994) en el artículo de Vega-Centeno (1998). Recientemente ha habido propuestas loables para sistematizar críticamente los fechados absolutos del Formativo, como la de Velarde (1998). Lamentablemente, este autor nunca define tal estadio, sino que lo asume como la unión del Periodo Inicial y el Horizonte Temprano. Esto demuestra el poco valor de las listas de fechados calibrados si no se aclara el concepto que los hace significativos. 
Por lo indicado, las críticas constructivas sobre periodificación, serán las que vayan hacia delante de la secuencia maestra. Existen diversas tendencias dentro de la arqueología peruana y latinoamericana actual, sin embargo la coordinación cronológica relativa a nivel nacional sigue siendo un imperativo permanente 45 . No parece que la periodificación se haya transformado aún en una cuestión de museo, o tal vez sí —en el sentido positivo—, ya que sigue marcando sus guiones, que son la forma básica de conexión entre los arqueólogos y el público. Sucede lo mismo con los manuales, que constituyen —largamente- el rubro más consumido de la disciplina46. A las críticas ya mencionadas (Mason, 1978 [1957]; Lumbreras, 1969a; Kaulicke, 1994, inter alia) debe agregarse una serie de observaciones aisladas pero no escasas. Estas van desde lo general hasta lo específico, y en este segundo rubro la mayoría está destinada al componente más temprano de la secuencia maestra: el Horizonte Temprano 47.

Según la escueta definición clásica, el Horizonte Temprano, es: «[...] the time from the first appearance of Chavín influence at Ica until polychrome slip painting replaces resin painting in that valley» (Rowe, 1962: 49). Al caracterizar la primera parte de este periodo, Menzel (1971 [1961]: 23-24) especificó más los elementos implicados:

«Para fines prácticos, el archivo arqueológico del valle de Ica comienza con el estilo de Cerrillos, que era aproximadamente contemporáneo con el clásico estilo Chavinoide (Curayacu) de la costa central (Lanning, MS.b). Dawson opina que es probable que eventualmente se llegue a descubrir una fase ligeramente anterior al estilo de Cerrillos con rasgos aún más semejantes a los Chavinoides de la costa central, por lo cual dicho estilo de Cerrillos podrá resultar contemporáneo con una última fase del estilo Curayacu C o con Curayacu D. Lanning ha calculado una antigüedad aproximada de 700 a 500 años A.C. para los estilos Curayacu C y D, sobre la base de las pruebas con el Carbono 14 utilizadas en relación a los estilos conexos de la costa del Norte».

Esta cita muestra cómo se compaginó el inicio del Horizonte Temprano. Sin una secuencia para el Periodo Inicial en Ica, Rowe (1959a: 9) decidió utilizar la información de la tesis de Lanning (1960) para la Costa Central, que mostraba la relación entre los estilos Cerrillos, Curayacu II y una variedad de Cupisnique, vinculados por detalles iconográficos chavín y rasgos técnicos de la cerámica. Según la síntesis posterior del propio Lanning (1967: 107) el trance estaba claramente marcado en Curayacu. Mientras en la ocupación del Periodo Inicial de este sitio hubo un estilo cerámico puro de la costa central y sin vasijas importadas, el Horizonte Temprano comenzaba con el súbito flujo de piezas típicas del estilo chavín indudablemente norteñas, y la proliferación de diseños mitológicos y patrones de textura (texturing devices) chavín en vasijas locales y artefactos óseos. Simultáneamente, apareció vajilla de intercambio no-Chavín de la costa sur y de la sierra. Los diseños mitológicos

45 Aunque no hay nada parecido a un consenso continental. Véase, por ejemplo, Borrero (1993) para Argentina.

46 Sobre esto último, basta verificar la lista de textos reeditados y traducidos: Bennett \& Bird (1949), Bushnell (1962 [1956]), Mason (1978 [1957]), Lumbreras (1969b). Entre los solo reeditados: Keatinge (1988), Moseley (2001 [1992]), Morales (1993). El libro de Lanning (1967) ha sido recientemente traducido.

47 Por cuestiones de espacio, y considerando que en términos conceptuales, las críticas a los Periodos y Horizontes siguientes deberían ser análogas, no se les tratará. La cerámica del Periodo Inicial de Ocucaje no fue sometida a una clasificación específica, ver adelante. Por definición, el Precerámico no forma parte de la secuencia maestra (ya que se trata de una secuencia cerámica). En todo caso, su división ha sido la más criticada, menos defendida, y — prácticamente - descartada. Ver las observaciones de Fung (1969), Bonavia (1991) y Chauchat (en Keatinge, 1988). 
fueron usados por uno o dos siglos, pero luego solo perduraron los patrones de textura para decorar la superficie exterior de las vasijas, antes usados para el interior. Luego Lanning aludía a otros sitios donde se daba un fenómeno semejante. Resumiendo los hallazgos de sus colegas (Menzel et al., 1964; Rowe, 1962), indicaba que en Paracas los diseños mitológicos chavín habían perdurado un largo tiempo, e incluso, las modificaciones en los detalles de las figuras reflejaban los cambios en la escultura lítica de Chavín de Huántar, indicando contactos sucesivos (Lanning, 1967: 108).

Se ha aludido a esta serie de definiciones para mostrar diversos ángulos de un mismo concepto: el inicio del Horizonte Temprano, el lapso más conflictivo de la secuencia maestra. Esta articulación de distintas secuencias (Chavín de Huántar $\rightarrow$ Curayacu $\rightarrow$ Ocucaje) puede ser lógicamente extrapolada, reconociendo los siguientes elementos:

a. el estilo chavín, que - justificando su denominación - se habría originado en el sitio epónimo y luego aparecería en Ocucaje.

b. la influencia chavín, este término implicaría la presencia alternativa y no excluyente de:

i) vasijas de Chavín de Huántar (con el estilo del mismo nombre),

ii) vasijas de manufactura local con rasgos chavín,

iii) vasijas de áreas intermedias (p.e. Curayacu) con la impronta chavín,

iv) vasijas locales con rasgos del estilo chavín de las áreas intermedias.

Aunque las variables pueden incrementarse exponencialmente (incluyendo zonas nointermedias; otro tipo de rasgo diagnóstico en la cerámica [p.e. técnicas de producción, composición de pastas, etc.]; otro tipo de soporte [p.e. textiles, madera, hueso, etc.]) las mencionadas son suficientes para mostrar las múltiples aristas de esta definición y situar las críticas48.

Shelia y Thomas Pozorski plantearon dos tipos de cuestionamientos. Por un lado indicaron que era muy difícil relacionar el material del valle que excavaban (Moche) con el de la secuencia maestra (Burger, 1988: 108). En segundo lugar, negaron la existencia de un Horizonte Chavín, proponiendo que el Horizonte Temprano debía denominarse Periodo Temprano. Argumentaban que los componentes estilísticos ya existían desde hacía muchos siglos, y que la iconografía chavín no sería más que una variante del sistema ancestral (Pozorski \& Pozorski, 1987). Lo primero — que ha sido recurrentemente mencionado por diversos autores - ya había sido contemplado en la propia definición de Rowe (1959a: 11-12, que alude al caso del Altiplano), ya que es imposible que todas las áreas presenten piezas de intercambio directo. Precisamente esto permite ubicar las zonas donde hay vacíos por resolver, y en todo caso cabe recurrir a los fechados absolutos. El concepto de horizonte no asume que lo sucedido en Ica (presencia chavín) se repita en toda el área andina. Sobre la segunda crítica, Richard Burger (1989b: 552-555) ha compilado una serie de rasgos particulares, que le permiten sostener que el Horizonte chavín no es una quimera estilística. Este autor insiste en el valor heurístico del término, que funcionaria como un estilo de horizonte efectivo para reconocer el proceso cultural asociado.

Pese a trabajar con el esquema Rowe-Lanning, Burger ha sido uno de los más insistentes (y citados) críticos de la secuencia maestra. Su cuestionamiento alude al concepto de influencia chavín. Según Burger (1988: 109-110) las piezas de intercambio chavín llegaron varios

48 Las posibilidades de la relación entre Chavín y Paracas son discutidas en Menzel et al. (1964: 257-258). 
siglos antes que la incorporación de los motivos iconográficos chavín en la cerámica del estilo paracas de Ocucaje, aunque no indica detalles del tipo de cerámica intrusiva. Este es uno de los corolarios de las opciones de influencia arriba mencionadas, e implicaría un reajuste de la definición, no su anulación49. En todo caso, Anne Paul (1991: 9) ha refutado la propuesta de Burger criticando sus referencias cronológicas y su interpretación50. En una revisión general de la secuencia paracas, Paul (1991: 8-11) ha actualizado el tema insistiendo en algunos tópicos claves. Primero, la sucesiva modificación de las fechas atribuidas al inicio del Horizonte Temprano por los propios miembros de la escuela de Berkeley, principalmente debido al refinamiento de los métodos de fechado absoluto. Segundo, ha presentado la reformulación de Sarah Massey, que implica: anular las dos primeras fases (por ausencia de testimonio alternativo y la escasa muestra en que se basaban) y comprimir las 8 fases restantes en solo cuatro51. Tercero, ha mostrado la vigencia general de la secuencia reformada a partir de su contrastación con fechados radiocarbónicos.

Si bien la discusión aquí planteada podría extenderse, lo anterior es suficiente para sustentar una conclusión específica: que ninguna de las críticas reseñadas afecta el valor instrumental del Horizonte Temprano, aunque siempre será necesario hacer una serie de precisiones empíricas y ajustes conceptuales. Se ha utilizado estos cuestionamientos para evidenciar la importancia heurística de este tipo de herramientas. Reconocida la arbitrariedad de toda secuencia y la formalización excesiva que todo cuadro cronológico implica, cabe insistir en su carácter aún imprescindible. Al tratar de definir un elemento puntual de una sección de la secuencia maestra, ha aflorado un conjunto de interrogantes que fueron planteadas hace más de cuatro décadas y siguen vigentes (en su doble calidad de hipótesis y problemas). En términos generales: de acuerdo a la información disponible, cualquier avance en periodificación relativa no puede dejar de incorporar lo ya realizado localmente, que no viene a ser más que la tendencia asociada a la secuencia maestra; incluso para refutarla. Lamentablemente, en nuestro medio, la tendencia de los estadios todavía no ha suscitado por si misma interrogantes de tal especificidad, antes bien las ha soslayado: superponiendo bloques de secuencias para «sintetizar», cuando son obvias las desventajas de tal procedimiento. Invirtiendo la proposición de uno de los autores tratados, la gracia del Horizonte Temprano (y de conceptos similares) reside justamente en que dependa de una serie de definiciones (estilísticas y cronológicas) precisas. Esto evitará el reflujo de generalizaciones que insisten en la falacia de concebir el todo sin haber aclarado las pautas para organizar los detalles, es decir (cuando menos) los criterios de periodificación 52.

49 Aunque Bischof (1996: 75-76) ha optado por una secuencia evolutiva (alude al Formativo), algunas de sus observaciones críticas al concepto de Horizonte Temprano podrían resultar útiles en este sentido.

50 Las críticas de Paul (1991: 31, n. 14) a Burger (1988) son: a. los dos primeros fechados de su tabla no corresponden a asociaciones con niveles Ocucaje 3 sino 7 , según el propio D. Wallace, que obtuvo las muestras; $b$. cita pero no incluye un fechado (GX-1345) que, al realizar los promedios, envejece en tres siglos la fase Ocucaje 3 ; c. usa fechados de contextos inciertos o mal documentados. Los cuestionamientos de Burger (1988) estaban orientados a compaginar su fase Janabarriu (390-200 a.C.) con el inicio del Horizonte Temprano. A la crítica citada, se suma la de Massey (1991: 344, n. 2) para quien Ocucaje 3 precede a Janabarriu. Sintomáticamente, las observaciones de Inokuchi (1998: 176) sobre Kuntur Wasi (Cajamarca) van en el mismo sentido. Según los fechados radiocarbónicos, la fase homónima (700-450 a.C.) antecede a Janabarriu, de la que supuestamente era consecuencia.

51 Ver además Massey 1986: 27-39; Silverman 1991: 377-379; Cook 1999: 68-69. Una posición contraria a las anteriores —es decir favorable a la secuencia original—en Tellenbach 1998, I: 123-124.

52 La periodificación no puede aislarse de otras categorías, por lo que sería preciso plantear una discusión análoga sobre el concepto de área (corologías) y los criterios de clasificación social. 


\section{Agradecimientos}

A José Luis Pino, Daniel Dávila, Fiona Menzies, Sara Joffré, Alina Santa Cruz y George Lau. A Lita Gamero, que —un buen día- me regaló los libros que sirvieron de base para este artículo. El núcleo de este texto fue presentado en el Congreso de Estudiantes de Arqueología del Cuzco (noviembre 1994) y apareció en la Revista Investigaciones 4 (1994) del CEAR (UNMSM). La versión actual fue discutida en el evento Nuevas Tendencias en Arqueología II (Lima 2002). Finalmente, agradezco las sugerencias críticas de Augusto Oyuela-Caycedo y el lector anónimo.

\section{Referencias citadas $^{53}$}

ANÓNIMO, 1951 - Notes and News, South America. American Antiquity, 16 (4): 367.

ARMILLAS, P., 1957 - Cronología y Periodificación de la historia de América Precolombina, 61 p.; México: Escuela Nacional de Historia y Antropología.

ARSENAULT, D., 1995 - Balance de los estudios moche (Mochicas) 1970-1994. Segunda parte: Trabajos arqueológicos. Revista Andina, 13 (2): 443-480.

BENNETT, W., 1946 - The Central Andes. In: Handbook of South American Indians. vol. 2: The Andean Civilizations (Steward, J. H., ed.): 61-147; Washington: United States Government Printing Office.

BENNETT, W. (comp.), 1948 - A Reappraisal of Peruvian Archaeology, 128 p.; Menasha: Society for American Archaeology/Institute of Andean Research.

BENNETT, W. \& BIRD, J., 1949 - Andean Culture History, 319 p.; New York: The Natural History Press. [2a edición, corregida-aumentada, 257 p., 1960] [Versión castellana de la primera edición, Rosalía Ávalos, 141 p.; Lima: Museo de Arqueología y Etnología de la Universidad Nacional Mayor de San Marcos, 1952].

BISCHOF, H., 1996 - Análisis iconográfico y del estilo en la elaboración de cronologías: el caso del formativo centroandino. Andes. Boletín de la Misión Arqueológica Andina. Universidad de Varsovia, 1: 61-91.

BONAVIA, D., 1991 - Perú hombre e historia. De los orígenes al siglo XV, 586 p.; Lima: Edubanco.

BONAVIA, D. \& MATOS, R., 1985 - Edward P. Lanning y la arqueología peruana. Revista del Museo Nacional, 47: 341-353.

BORRERO, L., 1993 - Artefactos y evolución. Palimpsesto. Revista de Arqueología, 3: 5-32.

BROWMAN, D., 1976 - Reseña a Lumbreras (1974). American Anthropologist, 78: 190-191.

BURGER, R., 1988 - Unity and heterogeneity within Chavín horizon. In: Peruvian Prehistory (Keatinge R., ed.): 100-144; Cambridge: Cambridge University Press.

BURGER, R., 1989a - An Overview of Peruvian Archaeology (1976-1986). Annual Review of Anthropology, 18: 37-69.

BURGER, R., 1989b - El horizonte Chavín: ¿Quimera estilística o metamorfosis socioeconómica? Revista Andina, 7 (2): 543-573.

BUSHNELL, G.,1962 [1956] - Perú, 212 p.; Barcelona: Argos.

53 En el caso de los manuales (síntesis) de arqueología peruana en inglés, las referencias se toman de la edición original. De haber traducción castellana, se cita la primera edición, y se indica la fecha original de publicación [entre corchetes] para respetar el orden cronológico. Toda excepción va indicada. 
CARDOSO, C., 1982 - Introducción al trabajo de la investigación histórica, 218 p.; Barcelona: Crítica.

CASTILLO, L., 2001 - Rafael Larco Hoyle y la vigencia de su obra. In: Los Mochicas (vol. 1) (Larco Hoyle, R.): XVIII-XXV; Lima: Museo Arqueológico Rafael Larco Herrera/ Fundación Telefónica.

CHOY, E., 1960 - La revolución Neolítica en los Orígenes de la Civilización Americana. In: ANTIGUO PERÚ. Espacio y Tiempo... (Matos, R., ed.): 149-198; Lima: Editorial Juan Mejía Baca.

CHOY, E., 1987 [1967] - La revolución mesolítica. In: Antropología e historia (vol. 1): 113-121; Lima: Universidad Nacional Mayor de San Marcos, 1987.

CHOY, E., 1969 - Circunstancias en que la contrarrevolución sirvió como factor de desarrollo en la revolución neolítica. In: Mesa Redonda de Ciencias Prehistóricas y Antropológicas (vol. 2): 56-61; Lima: Pontificia Universidad Católica del Perú.

COLLIER, D., 1960 [1955] - El desarrollo de la civilización en la costa del Perú. In: Las civilizaciones antiguas del Viejo Mundo y de América (Steward, J., ed.): 20-28; Washington D.C.: Unión Panamericana.

COOK, A., 1999 - Asentamientos Paracas en el Valle Bajo de Ica, Perú. Gaceta Arqueológica Andina, 25: 61-90.

DILLEHAY, T., 1996 - Reseña a Del Busto (editor general) [incluye reseña a Kaulicke, 1994]. Latin American Antiquity, 7 (3): 281-284.

FLANNERY, K., 1994 - Childe the evolutionist. A perspective from Nuclear America. In: The Archaeology of V. Gordon Childe (Harris, D. R., ed.): 101-112; London: University College of London.

FUNG, R., 1965 - Arqueología, ciencia histórica. Un ensayo crítico de los métodos y las teorías en la arqueología peruana, 131 p.; Lima: Universidad Nacional Mayor de San Marcos.

FUNG, R., 1969 - Observaciones arqueológicas sobre la obra: Perú antes de los Incas. Tecnia, 3: 142-152; Lima: Universidad Nacional de Ingeniería.

HAMMEL, E., 1969 - Peck's Archaeologist. The Kroeber Anthropological Society Papers, 40: 93-99.

INOKUCHI, K., 1998 - La cerámica de Kuntur Wasi y el problema Chavín. In: Perspectivas regionales del periodo formativo en el Perú (Kaulicke, P., ed.). Boletín de Arqueología PUCP, 2: 161-180. Lima: Pontificia Universidad Católica del Perú.

ISBELL, W., 1995 - Constructing the Andean Past or «As you like it». Journal of the Steward Anthropological Society, 23 (1/2): 1-12.

KAULICKE, P., 1994 - Los orígenes de la civilización andina. Historia General del Perú, 606 p.; Lima: Editorial Brasa.

KAULICKE, P. (ed.), 1998 - Perspectivas regionales del periodo formativo en el Perú. Boletín de Arqueología PUCP, 2; Lima: Pontificia Universidad Católica del Perú.

KEATINGE, R. (comp.), 1988 - Peruvian Prehistory. An overview of pre-Inca and Inca society, 364 p.; Cambridge: Cambridge University Press.

KROEBER, A., 1942 - Los Métodos de la Arqueología Peruana. Letras. Órgano de la Facultad de Letras y Pedagogía, 22: 205-226.

KROEBER, A., 1944 - Peruvian Archeology in 1942, 151 p.; New York: The Viking Fund.

KUBLER, G., 1985 [1970] - Period, Style and meaning in Ancient American Art. In: Studies in Ancient American and European Art. The collected essays of George Kubler: 395-405; New Haven/London: Yale University Press. 
LANNING, E., 1960 - Chronological and Cultural Relationships of Early Pottery Styles in Ancient Peru, 617 p.; Tesis de Doctorado, Universidad de California (2 vols.).

LANNING, E., 1967 - Peru Before the Incas, 216 p.; New Jersey: Prentice Hall.

LARCO, R., 1938 - Los mochicas (vol. 1), 144 p.; Lima: Casa editora La Crónica y Variedades.

LARCO, R., 1946 - A Cultural Sequence for the North Coast of Perú. In: Handbook of South American Indians. vol. 2: The Andean Civilizations (Steward, J., ed.): 149-175; Washington: United States Government Printing Office.

LARCO, R., 1948 - Cronología arqueológica del Norte del Perú, 87 p.; Buenos Aires: Sociedad Geográfica Americana.

LARCO, R., 1963 - Las épocas peruanas, 83 p.; Lima: Santiago Valverde.

LATHRAP, D., 1966 - Reseña a Rowe, Menzel \& Dawson (1964). American Antiquity 31 (6): 889-891.

LATHRAP, D., 1969 - Reseña a Lanning (1967). American Antiquity, 34 (3): 341-345.

LUMBRERAS, L., 1969a - Acerca del desarrollo cultural en los Andes. In: Mesa Redonda de Ciencias Prehistóricas y Antropológicas (13-18 octubre 1965) (vol. 2): 125-154; Lima: Pontificia Universidad Católica del Perú.

LUMBRERAS, L., 1969b - De los pueblos, de las culturas y las artes del Antiguo Perú, 379 p.; Lima: Moncloa-Campodónico editores.

LUMBRERAS, L., 1981 - Arqueología de la América Andina, 278 p.; Lima: Milla Batres.

LUMBRERAS, L., 1990 - Esbozo crítico de la arqueología. Gaceta Arqueológica Andina, 5 (17): 3-7.

LUMBRERAS, L. (ed.), 1999 - Historia de América Andina. vol. 1: Las sociedades aborígenes, 605 p.; Quito: Universidad Andina Simón Bolívar.

MACERA, P., 1988 [1968] - El historiador frente a la historia. El caso peruano. (Debate Araníbar-Choy-Lumbreras-Macera-Rivera). In: Trabajos de historia (vol. 1): 71-117; Lima: Universidad Nacional Mayor de San Marcos. 2a ed.

MACERA, P., 1978 - Visión histórica del Perú, 272 p.; Lima: Milla Batres.

MAKOWSKI, K., 1995 - El tiempo y la prehistoria: reflexiones sobre la naturaleza del hecho en la arqueología andina. Boletín del Instituto Riva-Agüero, 22: 163-176.

MASSEY, S., 1986 - Sociopolitical Change in the Upper Ica Valley, B.C. 400 to 400 A.D.: Regional States on the South Coast of Peru, 349 p.; Tesis de Doctorado, Universidad de California, Los Angeles.

MASSEY, S., 1991 - Social and political Leadership in the Lower Ica Valley. In: Paracas. Art \& Architecture. Object and Context in South Coastal Peru (Paul, A., ed.): 315-348; lowa: University of lowa Press.

MASON, J. A., 1978 [1957] - Las antiguas culturas del Perú, 313 p.; México: Fondo de Cultura Económica.

MATOS, R. (ed.), 1960 - ANTIGUO PERÚ. Espacio y Tiempo. Trabajos presentados a la Semana de Arqueología Peruana (9-14 de noviembre de 1959), 400 p.; Lima: Editorial Juan Mejia Baca.

MATOS, R., 1990 - Arqueología peruana (1970-1990): Algunos comentarios. Revista Andina, 8 (2): 507-553.

MENZEL, D., 1960 - El panorama actual de la Arqueología Peruana. Revista del Museo Regional de Ica, 12: 30-37.

MENZEL, D., 1964 - Style and Time in Middle Horizon. Nawpa Pacha, 2: 1-106.

MENZEL, D., 1969 - Some of Rowe's Contributions in the Field of Andean Culture History. The Kroeber Anthropological Society Papers, 40: 100-111. 
MENZEL, D., 1971 [1961] - Estudios arqueológicos en los valles de Ica, Pisco, Chincha y Cañete. Arqueología y Sociedad, 6: 1-161.

MENZEL, D., 1976 - Pottery Style and Society in Ancient Peru. Art as a Mirror of History in the Ica Valley, 1350-1570, 275 p.; Berkeley: University of California Press.

MENZEL, D., ROWE, J. \& DAWSON, L., 1964 - The Paracas Pottery of Ica: a Study in Style and Time, 399 p.; Berkeley/Los Angeles: University of California Press.

MORALES, D., 1993 - Historia Arqueológica del Perú (del paleolítico al imperio Inca), 676 p.; Lima: Milla Batres.

MORRIS, C. \& HAGEN, A. von, 1993 - The Inca Empire and its Andean origins, 220 p.; New York/London/Paris: Museum of Natural History/ Abbeville Press.

MOSELEY, M., 2001 [1992] - The Incas and their ancestors. The Archaeology of Peru, 288 p.; London: Thames and Hudson.

MUELLE, J., HAMMEL, E. \& LANNING, E., 1958 - Sobre el concepto de horizonte en la arqueología peruana. Anales de la UNMSM Segunda época, 19/20: 72-74.

NACHTINGAL, H., 1969 - Remarks on the Classifications of the Peruvian Archaeological Cultures. In: Verhandlungen des XXXVIII. Internationalen AmerikanistenKongresses. Stuttgart-München, 12-18. August 1968 (vol. 1): 323-335; München: Komissionsverlag Klaus Renner.

OTTONELLO, M. M. \& LORANDI, A. M., 1987 - Introducción a la arqueología y Etnología. Diez mil años de Historia Argentina, 210 p.; Buenos Aires: Eudeba.

PANOFSKY, E., 1991 [1951] - Arquitetura gótica e escolástica. Sobre a analogia entre arte, filosofia e teologia na Idade Média, 133 p.; São Paulo: Martins Fontes.

PATTERSON, T., 1963 - Contemporaneity and Crossdating in Archaeological Interpretation. American Antiquity, 28 (3): 389-392.

PATTERSON, T., 1966 - Pattern and Process in the Early Intermediate Period Pottery of the Central Coast of Peru, 180 p.; Berkeley/Los Angeles: University of California Press.

PATTERSON, T., 1989 - Political Economy and a Discourse called «Peruvian Archaeology». Culture and History, 4: 35-64.

PAUL, A., 1991 - Paracas. An Ancient Cultural Tradition on the South Coast of Peru. In: Paracas. Art \& Architecture. Object and Context in South Coastal Peru (Paul, A., ed.): 1-34; lowa: University of lowa Press.

PORRAS, R., 1963 - Fuentes Históricas Peruanas (Apuntes de un curso universitario), 606 p.; Lima: Instituto Raúl Porras.

POZORSKI, T. \& POZORSKI, S., 1987 - Chavin, the Early Horizon and the Initial Period. In: The Origins and Development of the Andean State (Haas, J., Pozorski, S., Pozorski, T., eds.): 36-46; Cambridge: Cambridge University Press.

PROUS, A., 1992 - Arqueología Brasileira, 605 p.; Brasilia: Editora Universidade de Brasilia.

RAMÓN, G., 1994 - Reseña a Morales (1993). Histórica, 18 (1): 193-198.

RAMÓN, G., 2000 - Reseña a Riviale (2000). Bulletin de l'Institut Français d' Etudes Andines, 30 (1): 175-179.

RAVINES, R. (comp.), 1970 - Cien años de arqueología peruana, 611 p.; Lima: IEP.

RAVINES, R., 1994 - Las culturas preincas. Arqueología del Perú. Historia General del Perú, 606 p.; Lima: Editorial Brasa.

RENFREW, C. \& BAHN, P., 1993 - Arqueología. Teoría, métodos y práctica, 571 p.; Madrid: Akal. 
RICHARDSON, J., 1994 - People of the Andes, 176 p.; Montreal/Washington: St. Remy Press/ Smithsonian Books.

RIVIALE, P., 2000 - Los viajeros franceses en busca del Perú Antiguo (1821-1914), 456 p.; Lima: Instituto Francés de Estudios Andinos/Pontificia Universidad Católica del Perú.

ROSELLÓ, L., 1985 - Los esquemas crono-evolutivos de Tello. Histórica, 9 (2): 275-290.

ROUSE, I., 1975 - Reseña a Lumbreras (1974). Science, 188: 144.

ROWE, J., 1945 - Absolute chronology in the Andean area. American Antiquity, 10 (3): 265-284.

ROWE, J., 1948 - On absolute dating and north coast history. In: A Reappraisal of Peruvian Archaeology (Bennett, W., comp.): 51-52; Menasha: Society for American Archaeology/ Institute of Andean Research.

ROWE, J., 1949 - Reseña a Bennett y Bird (1949). Hispanic American Historical Review, 29 (4): 598-600.

ROWE, J., 1950 - Reseña a Bennett y Bird (1949). American Antiquity, 16 (2): 170-172.

ROWE, J., 1951 - Andean Culture History. An Apology and Clarification. American Antiquity, 16 (4): 356.

ROWE, J., 1953 - Reseña a George Murdock (1951). American Antiquity, 18 (3): 279-280.

ROWE, J., 1954 - Max Uhle, 1856-1944. A memoir of the father of Peruvian archaeology, 134 p.; Berkeley/ Los Angeles: University of California Press.

ROWE, J., 1956 - Archaeological Explorations in Southern Perú, 1954-1955. Preliminary Report of the Fourth University of California Archaeological Expedition to Peru. American Antiquity, 22 (2): 135-151.

ROWE, J., 1957 - L.E. Dawson's seriation of Paracas pottery, 7 p.; Berkeley. Separata mimeografiada.

ROWE, J., 1959a - Terminología en Arqueología Peruana. Exposición en el Museo de Arqueología de la Universidad San Marcos. 25. vol. 1, 12 p.; Manuscrito de Hernán Amat Olazábal. [Colección J.L. Pino]. Ms.

ROWE, J., 1959b - Archaeological dating and cultural process. Southwestern Journal of Anthropology, 15: 317-324.

ROWE, J., 1960a [1959] - Tiempo, estilo y proceso cultural en la arqueología peruana, 16 p.; Berkeley: Instituto de Estudios Andinos. 2aㅡ ed.

ROWE, J., 1960b - Nuevos datos relativos a la cronología del estilo Nasca. In: ANTIGUO PERÚ. Espacio y Tiempo... (Matos, R., ed.): 29-46; Lima: Editorial Juan Mejía Baca.

ROWE, J., 1960c - Reseña a Uhle (1959). American Antiquity, 25 (4): 618.

ROWE, J., 1961 - Stratigraphy and Seriation. American Antiquity, 26 (3): 324-330.

ROWE, J., 1970 [1961] - La Arqueología de Ica. In: 100 años de Arqueología en el Perú (Ravines, R., ed.): 415-437; Lima: Instituto de Estudios Peruanos.

ROWE, J., 1962 - Stages and Periods in Archaeological Interpretation. Southwestern Journal of Anthropology, 18 (1): 40-54.

ROWE, J., 1975 - Reseña a Willey \& Sabloff. A History of American Archaeology. Antiquity, 49: 156-158.

ROWE, J., 1998 - Max Uhle y la idea del tiempo en la arqueología americana. In: Max Uhle y el Perú Antiguo, (Kaulicke, P., ed.): 5-21; Lima: Pontificia Universidad Católica del Perú.

ROWE, J. \& MENZEL, D. (eds.), 1967 - Peruvian Archaeology. Selected readings, 320 p.; California: Peek Publications. 
SCHAEDEL, R. \& SHIMADA, I., 1982 - Peruvian archaeology, 1946-80: an analytic overview. World Archaeology 13: 359-371.

SILVA, J., 2000 - Origen de las civilizaciones andinas. In: Historia del Perú: 15-173; Barcelona: Lexus editores.

SILVERMAN, H., 1991 - The Paracas Problem. Archaeological Perspectives. In: Paracas. Art \& Architecture. Object and Context in South Coastal Peru, (Paul, A., ed.): 349-415; lowa: University of lowa Press.

SILVERMAN, H., 1996 - The Formative Period on the South Coast of Peru: A critical Review. Journal of World Prehistory, 10 (2): 95-146.

STEWARD, J., 1948 - A Functional-Developmental Classification of American High Cultures. In: A Reappraisal of Peruvian Archaeology (Bennett, W., comp.): 103-104; Menasha: Society for American Archaeology/ Institute of Andean Research.

STONE-MILLER, R., 1993 - An Overview on «Horizon» and «Horizon Style» in the Study of Ancient American Objects. In: Latin American Horizons, A Symposium Dumbarton Oaks, $11^{\text {th }}-12^{\text {th }}$ October 1986 (Rice, D. S., ed.): 15-39; Washington D.C.: Dumbarton Oaks.

STONE-MILLER, R., 1995 - Art of the Andes. From Chavín to Inca, 223 p.; New York: Thames and Hudson.

STRONG, W., 1948 - Cultural Epochs and Refuse Stratigraphy in Peruvian Archaeology, In: A Reappraisal of Peruvian Archaeology (Bennett, W., comp.): 93-102; Menasha: Society for American Archaeology/ Institute of Andean Research.

TABIO, E., 1965 - Excavaciones en la Costa Central del Perú (1955-1958), 108 p.; La Habana: Departamento de Antropología. Academia de Ciencias.

TELLENBACH, M., 1998 - Chavín. Investigaciones acerca del desarrollo cultural CentroAndino en las épocas Ofrendas y Chavín-Tardío. Andes. Boletín de la Misión Arqueológica Andina. Universidad de Varsovia, 2 (2 vols.).

TELlO, J., 1929 - Antiguo Perú. Primera época, 183 p.; Lima: Editado por la Comisión Organizadora del Segundo Congreso Sudamericano de Turismo.

TELLO, J., 1942 [1939] - Origen y desarrollo de las civilizaciones prehistóricas andinas, 132 p.; Lima: Librería e imprenta Gil.

TELLO, J., 1980 [1932] - Origen, desarrollo y correlación de las antiguas culturas peruanas. Histórica, 4 (1): 95-108.

UHLE, M., 1902 - Types of culture in Peru. American Anthropologist, N.S., 4 (4): 753-759.

Uhle, M., 1903 - Pachacamac, 103 p.; Philadelphia: University of Pennsylvania.

UHLE, M., 1970 [1910] - Las civilizaciones primitivas en los alrededores de Lima. In: Cien años de Arqueología en el Perú (Ravines, R., ed.): 379-391; Lima: Instituto de Estudios Peruanos.

UHLE, M., 1920 - Los principios de las antiguas civilizaciones peruanas. Boletín de la Sociedad Ecuatoriana de Estudios Históricos Americanos, 4 (12): 448-458.

UHLE, M., 1955 [1939] - Las antiguas civilizaciones del Perú frente a la Arqueología e Historia del Continente Americano. Boletín de la Academia Nacional de Historia, 35 (85): 5-42.

VAlCÁRCEL, L., 1967 - Etnohistoria del Perú Antiguo. Historia del Perú (Incas), 252 p.; Lima: Universidad Nacional Mayor de San Marcos.

VARIOS, 1953 - Actas de la Mesa Redonda sobre Terminología Arqueológica. Boletín de la Sociedad para la Antropología Peruana, 1; Lima. 
VARIOS, 1958 - Actas de la Mesa Redonda de Ciencias Antropológicas. Lima: Instituto de Etnología y Arqueología Universidad Nacional Mayor de San Marcos. Mimeografiadas.

VARIOS, 1959 - Actas y Trabajos del II Congreso Nacional de Historia del Perú. vol. 1: Época Prehispánica. 4 al 9 de agosto de 1958, 380 p.; Lima: Centro de Estudios Histórico Militares.

VEGA-CENTENO, R., 1998 - Patrones y convenciones en el arte figurativo del Formativo Temprano en la Costa Norte de los Andes Centrales. Bulletin de I' Institut Français d'Études Andines, 27 (2): 183-211.

VELARDE, L., 1998 - Problemática de los fechados carbono 14 y su calibración: el caso del formativo de los andes centrales. Arqueología y Sociedad, 12: 11-28.

WILLEY, G., 1946a - The Chiclín Conference for Peruvian Archaeology. American Antiquity, 12 (2): 132-134.

WILLEY, G., $1946 \mathrm{~b}$ - Proyecto de investigaciones andinas para el valle del Virú. Revista del Museo Nacional, 15: 57-61.

WILLEY, G., 1951 - Peruvian horizon styles. American Antiquity, 16 (4): 353-354.

WILLEY, G., 1971 - An Introduction to American Archaeology. vol. 2: South America, 559 p.; New Jersey: Prentice-Hall.

WILLEY, G., 1999-The Virú Valley Project and Settlement Archaeology. Some Reminiscences and Contemporary Comments. In: Settlement Pattern Studies in the Americas. Fifty years since Virú (Billman, B. \& Feinman, F., eds.): 9-11; Washington/London: Smithsonian Institution Press.

WILLEY, G. \& PHILLIPS, P., 1970 [1958] - Method and Theory in American Archaeology, 270 p.; Chicago: University of Chicago Press. 6 $\underline{a}$ impresión. 